\title{
Cloud-system resolving model simulations of aerosol indirect effects on tropical deep convection and its thermodynamic environment
}

\author{
H. Morrison and W. W. Grabowski \\ Mesoscale and Microscale Meteorology Division, NCAR Earth System Laboratory, National Center for Atmospheric \\ Research, Boulder, CO 80305, USA
}

Received: 19 March 2011 - Published in Atmos. Chem. Phys. Discuss.: 23 May 2011

Revised: 9 September 2011 - Accepted: 4 October 2011 - Published: 24 October 2011

\begin{abstract}
This paper presents results from 240-member ensemble simulations of aerosol indirect effects on tropical deep convection and its thermodynamic environment. Simulations using a two-dimensional cloud-system resolving model are run with pristine, polluted, or highly polluted aerosol conditions and large-scale forcing from a 6-day period of active monsoon conditions during the 2006 Tropical Warm Pool - International Cloud Experiment (TWP-ICE). Domain-mean surface precipitation is insensitive to aerosols primarily because the large-scale forcing is prescribed and dominates the water and static energy budgets. The spread of the top-of-atmosphere (TOA) shortwave and longwave radiative fluxes among different ensemble members for the same aerosol loading is surprisingly large, exceeding $25 \mathrm{~W} \mathrm{~m}^{-2}$ even when averaged over the 6-day period. This variability is caused by random fluctuations in the strength and timing of individual deep convective events. The ensemble approach demonstrates a small weakening of convection averaged over the 6-day period in the polluted simulations compared to pristine. Despite this weakening, the cloud top heights and anvil ice mixing ratios are higher in polluted conditions. This occurs because of the larger concentrations of cloud droplets that freeze, leading directly to higher ice particle concentrations, smaller ice particle sizes, and smaller fall velocities compared to simulations with pristine aerosols. Weaker convection in polluted conditions is a direct result of the changes in anvil ice characteristics and subsequent upper-tropospheric radiative heating and weaker tropospheric destabilization. Such a conclusion offers a different interpretation of recent satellite observations of tropical deep convection in pristine and polluted environments compared
\end{abstract}

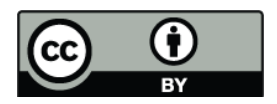

Correspondence to: $\mathrm{H}$. Morrison (morrison@ucar.edu) to the hypothesis of aerosol-induced convective invigoration. Sensitivity tests using the ensemble approach with modified microphysical parameters or domain configuration (horizontal gridlength, domain size) produce results that are similar to baseline, although there are quantitative differences in estimates of aerosol impacts on TOA radiative fluxes.

\section{Introduction}

Anthropogenic change of Earth's climate is one of the biggest challenges facing humankind in the 21 st century. The last several decades have featured increasing awareness of the growing levels of atmospheric carbon dioxide and other greenhouse gases and their impact on climate (Solomon et al., 2007). At the same time, other anthropogenic impacts on the climate system have been identified, including direct, semi-direct, and indirect effects of anthropogenic aerosols. The direct impact is associated with changes in the transfer of solar and longwave radiation due to scattering and absorption by the aerosol particles. Semi-direct effects involve changes in clouds resulting from the impact of aerosols on atmospheric stratification through radiative heating (e.g. Hansen et al., 1997; Ackerman et al., 2000). Indirect effects, on the other hand, are associated with modification of atmospheric aerosols that serve as cloud condensation nuclei $(\mathrm{CCN})$ or ice nuclei (IN). Changes in the concentrations of CCN and IN affect cloud droplet and ice crystal concentrations and sizes, impacting radiative properties (e.g. Twomey, 1974, 1977) and development of precipitation via the collision/coalescence mechanism (e.g. Warner, 1968; Albrecht, 1989; Rosenfeld, 2000). Direct and indirect impacts of aerosols are thought to have a net cooling effect on the climate and thus may offset some warming associated with

Published by Copernicus Publications on behalf of the European Geosciences Union. 
increasing concentrations of greenhouse gases (Solomon et al., 2007). However, there are currently large uncertainties in the magnitude of these impacts (Solomon et al., 2007).

A critical aspect of aerosol-cloud interactions concerns possible changes in cloud dynamics as the aerosols are modified, via impacts on atmospheric or surface radiative heating associated with direct and semi-direct effects, or impacts on cloud microphysics through indirect effects. Coupling with the dynamics may be particularly important for deep convective clouds, where processes like latent heating and condensate loading, which are strongly influenced by cloud microphysics, determine buoyancy and therefore directly drive the convective motion field. Recent studies using cloud-system resolving models (CSRMs) with a horizontal grid spacing of order $1 \mathrm{~km}$ (e.g. Seifert and Beheng, 2006; van den Heever et al., 2006; Phillips et al., 2007; van den Heever and Cotton, 2007; Fan et al., 2007; Lee et al., 2008; Khain, 2009; Fan et al., 2009; Lebo and Seinfeld 2011; Ekman et al., 2011; see review in Levin and Cotton, 2009) have suggested that aerosols can either invigorate or weaken convective cloud growth depending upon the particular model employed and a number of other factors including environmental conditions. A mechanism resulting in the invigoration of convection that has been proposed involves the following links (Khain et al., 2005; Koren et al., 2005; Rosenfeld et al., 2008): aerosol loading reduces the collision-coalescence production of rain drops, which in turn results in more cloud water ascending above the freezing level. This water subsequently freezes and releases latent heat. The delay in warm-rain formation and subsequent enhanced ice formation increases the latent heat release above the freezing level, invigorating the storm. However, in weak convection the updrafts can become water loaded before reaching the freezing level, while in intense updrafts raindrops as well as cloud droplets may be lofted above the freezing level and subsequently freeze. In these cases, aerosol loading and increased CCN have little effect or may even result in a weakening of the cloud dynamics (Seifert and Beheng, 2006). Furthermore, once cold pools form the response may be dominated by secondary convection initiated along the cold pool boundaries; model studies have shown both a weakening of secondary convection with aerosol loading (van den Heever and Cotton, 2007) as well as strengthening (Khain et al., 2005; Lynn et al., 2005; Lee et al., 2008). Studies have suggested that the response of storm dynamics and precipitation depends in part on environmental parameters like convective available potential energy (CAPE), environmental RH, and vertical wind shear (e.g. Khain, 2009; Fan et al., 2009).

While many studies have focused on the impact of changes in $\mathrm{CCN}$ concentration, modification of IN may also impact deep convective clouds. However, the relationship between aerosol loading and IN remains highly uncertain (Cantrell and Heysfield, 2005; Fridlind et al., 2007). Modeling studies have shown a wide spread in the response of convective intensity and surface precipitation to changes in IN concentra- tion (e.g. van den Heever et al., 2006; Connolly et al., 2006; Ekman et al., 2007; Fan et al., 2010). The response of deep convection to aerosols is further complicated by modification of $\mathrm{CCN}$ and hence the characteristics of cloud droplets, and their subsequent freezing and impact on ice characteristics (e.g. Ekman et al., 2011).

Observing aerosol impacts on clouds is difficult because of issues related to correlation versus causation and confounding meteorological factors (Stevens and Feingold, 2009). Recent satellite studies have examined correlations between cloud height, cloud fraction, and aerosols to infer that convection is invigorated in polluted conditions (Devasthale et al., 2005; Koren et al., 2005, 2008, 2010a, b; Meskhidze et al., 2009). For example, Koren et al. (2010a) used MODIS cloud top pressure and aerosol optical depth (AOD) data to conclude that cloud tops increase by $400 \mathrm{~m}$ per 0.1 increase in AOD (see their Fig. 9), and hypothesized that this was the result of convective invigoration. We note, however, that the majority of cloud tops sensed by MODIS (see Fig. 3 of Koren et al., 2010a) are primarily located at altitudes below $3 \mathrm{~km}$, while the altitude of deep convective outflow is typically above $10 \mathrm{~km}$. The more recent study of Massie et al. (2011) has suggested that while there is some evidence of an increase in height of clouds associated with deep convection (primarily anvils), the increase in cloud top height per unit increase in AOD is 2 to 10 times smaller than those calculated previously using MODIS data.

Single cloud or cloud-system simulations of the type discussed above are important for understanding interactions between microphysics and cloud dynamics. However, as far as the implications for climate are concerned, such simulations are limited. This is because they neglect the feedback between convection and its environment, occurring either through cloud dynamics or cloud microphysics (cf. Grabowski, 2006). Such interactions often obscure the effects of cloud microphysics (Stevens and Feingold, 2009). For example, if the latent heating profiles change with different aerosol loadings, as suggested by these studies, this implies a different convective response and hence change in the large-scale temperature profile and environment conditions in which subsequent clouds form. A similar argument can be made for the impact on precipitation and hence the water budget, where increased precipitation falling from the first cloud affects the availability of moisture and development of subsequent clouds.

Grabowski (2006), Grabowski and Morrison (2011), and van den Heever et al. (2011) examined such feedbacks with the environment in the context of convective-radiative quasiequilibrium (CRE) using a CSRM, which is arguably the simplest framework to examine these feedbacks. In CRE with fixed surface conditions, changes in domain-mean precipitation induced by aerosols can only result from changes in the atmospheric radiative cooling or Bowen ratio (ratio of surface sensible and latent heat fluxes), which was found to be negligible in the simulations of Grabowski (2006) and 
Grabowski and Morrison (2011). They found that changes in droplet concentration and hence warm rain production were compensated by other changes to the cloud and precipitation characteristics to give nearly the same surface precipitation rate as the aerosol loading was increased. There were significant impacts of aerosols on top-of-atmosphere (TOA) reflected shortwave (RSW) and outgoing longwave (OLR) radiative fluxes (several $\mathrm{W} \mathrm{m}^{-2}$ ), although the magnitude was sensitive to representation of cloud microphysics, among other factors. Van den Heever et al. (2011), using a domain size several times larger than that used in Grabowski (2006) and Grabowski and Morrison (2011), similarly found only a very weak response of the domain-mean precipitation to increased aerosol loading in the CRE simulations. However, they also noted more significant but offsetting impacts when partitioned into different convective modes (shallow, midlevel, and deep).

In this study, we utilize a CSRM with periodic lateral boundary conditions and fixed sea surface temperature (SST) to investigate aerosol indirect effects on tropical deep convection and outflow cirrus. In contrast to the CRE studies of Grabowski (2006) and Grabowski and Morrison (2011), the current study examines aerosol indirect effects using large-scale, time-evolving forcing (i.e. potential temperature and water vapor advection/divergence) based on observations during the Tropical Warm Pool - International Cloud Experiment (TWP-ICE; May et al., 2008). This approach, in the spirit of simulations reported in Grabowski et al. (1999), is utilized as a way to investigate to aerosolinduced changes in clouds and convection in a system that includes feedback with the environment and realistic, timedependent forcing, but without complications arising from feedbacks with larger scale dynamics. The simulated period of TWP-ICE was dominated by deep convection and heavy precipitation associated with the active monsoon. Given the inherent randomness associated with individual deep convective events, we use a large-member ensemble approach to generate robust statistics. Ensemble-based approaches for simulating the response of clouds and convection to different CSRM configurations and parameter settings have been previously used by Grabowski et al. (1999) and Khairoutdinov and Randall (2003). Here, simulations are run with quasiidealized representations of pristine, polluted, or highly polluted aerosol conditions, and impacts of aerosols on the clouds, precipitation, radiative fluxes, and cloud dynamics are analyzed in detail. Finally, we test the sensitivity of these impacts to the representation of various microphysical processes as well as horizontal gridlength and domain size.

The paper is organized as follows. Section 2 gives the model description and setup for this case. A brief description of the case study and experimental design is given in Sect. 3. Baseline results with pristine aerosols are presented in Sect. 4, and aerosol indirect effects are described in Sect. 5. Sensitivity of aerosol indirect effects to representation of microphysics and domain configuration is described in Sect. 6.
Finally, Sect. 7 provides discussion and summary of the main conclusions.

\section{Model description and configuration}

The dynamic model is the same as used in Grabowski (2006) and Grabowski and Morrison (2011). It is a two-dimensional (2-D) nonhydrostatic anelastic fluid flow model that was also used as the "superparameterization" in simulations descried in Grabowski and Smolarkiewicz (1999) and Grabowski (2001, 2004) and in cloud simulations described in Morrison et al. (2008a) and Grabowski et al. (2010). In the baseline configuration here, horizontal grid spacing is $1 \mathrm{~km}$ with a horizontal domain extent of $200 \mathrm{~km}$; sensitivity to horizontal grid spacing and domain size is described in Sect. 6.2. The model applies 97 vertical levels over a stretched grid, with a model top at $25 \mathrm{~km}$. The Monin-Obukhov surface similarity is used to calculate surface fluxes and a nonlocal boundary layer scheme (e.g. Troen and Mahrt, 1986) is applied to represent unresolved transport within the boundary layer.

The microphysics parameterization in the baseline configuration is the same as used by Grabowski and Morrison (2011), with modification for the sensitivity tests described in Sect. 6.1. The warm-rain scheme is the twomoment bulk scheme of Morrison and Grabowski (2007, 2008a). Ice processes are represented using the two-moment, three-variable scheme of Morrison and Grabowski (2008b). In this approach, the ice particle mass-dimension and projected area-dimension relationships vary as a function of particle size and rime mass fraction. Rime mass fraction is derived locally by separately predicting ice mixing ratios acquired through riming and vapor deposition. The third variable is the number concentration of ice particles. This approach allows for gradual transition of ice particles to graupel and avoids unphysical and arbitrary thresholds for graupel conversion that are used in most bulk and bin microphysics schemes. This scheme has been previously applied to kinematic, specified flow simulations of organized deep convection (Slawinska et al., 2009) and shallow, precipitating cumulus (Morrison et al., 2008b).

The radiative transfer model, the same as in Grabowski (2006) and Grabowski and Morrison (2011), comes from the National Center for Atmospheric Research (NCAR)'s Community Climate System Model (Kiehl et al., 1994). The effective radii of water droplets and ice crystals for the radiative transfer are calculated following the spectral characteristics and assumed mass-dimension and project area-dimension relationships for ice (see Morrison and Grabowski, 2008a, b). The effective radii predicted by the two-moment scheme are additionally limited to be between 4 and $20 \mu \mathrm{m}$ for water droplets and 13 and $130 \mu \mathrm{m}$ for ice. Such limiting is required to avoid unphysical values predicted by the two-moment in grid points with extremely 
small water or ice mixing ratios and problems when used to calculate optical properties.

\section{Case description and experimental design}

TWP-ICE took place in the vicinity of Darwin, Australia from 20 January to 13 February 2006 (May et al., 2008). This experiment specifically focused on the properties of outflow cirrus and their relationship to environmental conditions and convective characteristics. The TWP-ICE domain consisted of several ground sites that gathered precipitation, meteorological, and surface flux measurements, and was centered on a heavily-instrumented site operated by the US Department of Energy Atmospheric Radiation Measurement (ARM) Program and Australian Bureau of Meteorology that included cloud and scanning weather radars. The domain was surrounded by an array of five 3-hourly soundings. TWP-ICE was coordinated with the UK Aerosol and Chemical Transport in tropical convection (ACTIVE) experiment (Vaughan et al., 2008), which used two additional research aircraft to gather in-situ measurements of clouds and aerosols during the period November 2005 to February 2006 in the same region. Data used to compare with the model are based on a combination of near-surface meterological, sounding, and satellite measurements described by Xie et al. (2010).

The model setup is similar to that for the ARM/GCSS cloud model intercomparison (Fridlind et al., 2010). Largescale horizontal and vertical advective forcings of water vapor, $q$, and potential temperature, $\theta$, are derived from observations (Xie et al., 2010). These forcings are modified above $13 \mathrm{~km}$ to minimize drift in simulated profiles using an approach similar to Fridlind et al. (2010). We emphasize that the applied large-scale advective forcings are identical in all simulations. Horizontal wind above $500 \mathrm{~m}$ is nudged to observations with a 2-h timescale. Large-scale vertical advection of the prognostic cloud quantities is calculated using the specified large-scale vertical velocity and modeled quantities, while large-scale horizontal advection of cloud quantities is neglected. Initial conditions (horizontal wind, $\theta, q$ ) are derived from sounding observations (Xie et al., 2010). Random perturbations with a maximum amplitude of $\pm 0.25 \mathrm{~K}$ are applied to the $\theta$ field between heights of about 100 and $600 \mathrm{~m}$ every $30 \mathrm{~min}$ to represent under-resolved boundary layer heterogeneity. The simulated period is from 00:00 UTC 18 January to 12:00 UTC 25 January. We consider the first $36 \mathrm{~h}$ as model spin-up and focus the analysis on the 6-day period from 12:00 UTC 19 January to 12:00 UTC 25 January.

Aerosol conditions are given by a three-mode lognormal aerosol size distribution. Size distribution parameters for the modes of $0.03,0.18$, and $4.4 \mu \mathrm{m}$ for the mean radius and standard deviations of 1.12, 1.45, and 1.8 are specified as typical of active monsoon conditions based on Allen et al. (2008). For the pristine simulations (hereafter "PRIS"), total aerosol concentration is $354.4 \mathrm{~cm}^{-3}$, partitioned into the three modes as 259,95 , and $0.4 \mathrm{~cm}^{-3}$ (from smallest to largest mode), which is similar to relatively pristine conditions observed on 6 February (Allen et al., 2008). For the polluted simulations (hereafter "POLL"), the concentration of the smallest mode is increased by a factor of 10 , giving a total concentration of $2780.4 \mathrm{~cm}^{-3}$. This is similar to relatively polluted conditions observed on 16 November. Highly polluted conditions (SPOLL) are roughly based on typical urban aerosol conditions (Pruppacher and Klett, 1997), with the number concentrations of the small and middle modes increased by factors of 20 and 10, respectively, to give a total concentration of $6130.4 \mathrm{~cm}^{-3}$. Aerosol size distributions for PRIS, POLL, and SPOLL are shown in Fig. 1. For simplicity, background aerosols are assumed to be constant in time and space but we limit droplet activation so that it does not increase the concentration of newly activated plus existing cloud droplets above the background $\mathrm{CCN}$ concentration. We also neglect changes in concentrations of ice-forming nuclei (IN) with aerosol loading, although ice number concentration is affected by changes in droplet concentration and subsequent freezing.

\section{Baseline results}

Overall cloud and radiative characteristics are strongly driven by the imposed large-scale forcing. In all simulations, moist deep convection begins within the first few hours of integration, after which there are intermittent periods of intense deep convective motion and heavy precipitation, culminating with a peak domain-mean precipitation rate of about $11 \mathrm{~mm} \mathrm{~h}^{-1}$ on 23 January associated with passage of a vigorous mesoscale convective system. Convective towers at various stages in their lifecycle, including vigorous convection overshooting the tropopause and reaching heights of $\sim 19.5 \mathrm{~km}$, are interspersed throughout the model domain at any given time. Deep convective towers are more numerous during periods with heavier domain-mean precipitation. The convection also appears somewhat more organized during the period of intense precipitation on 23 January, with a region of multiple deep convective towers and heavy precipitation surrounded by lighter stratiform precipitation falling from mid- and upper-level clouds predominately composed of ice. Outflow clouds associated with these convective towers are prevalent across the upper-troposphere, with a time- and domain-mean hydrometeor fraction of about $95 \%$ near the tropopause (hydrometeor fraction is defined using a threshold hydrometeor mixing ratio larger than $10^{-4} \mathrm{~g} \mathrm{~kg}^{-1}$ ). These anvil clouds contain large amounts of ice water, especially during the period of intense convection and precipitation on 23 January. There is also a distinct mode of shallow convective clouds throughout most of the period.

As a first step to test robustness of these results, we examined sensitivity to initial conditions and large-scale forcing for PRIS. Tiny perturbations to these specifications resulted 


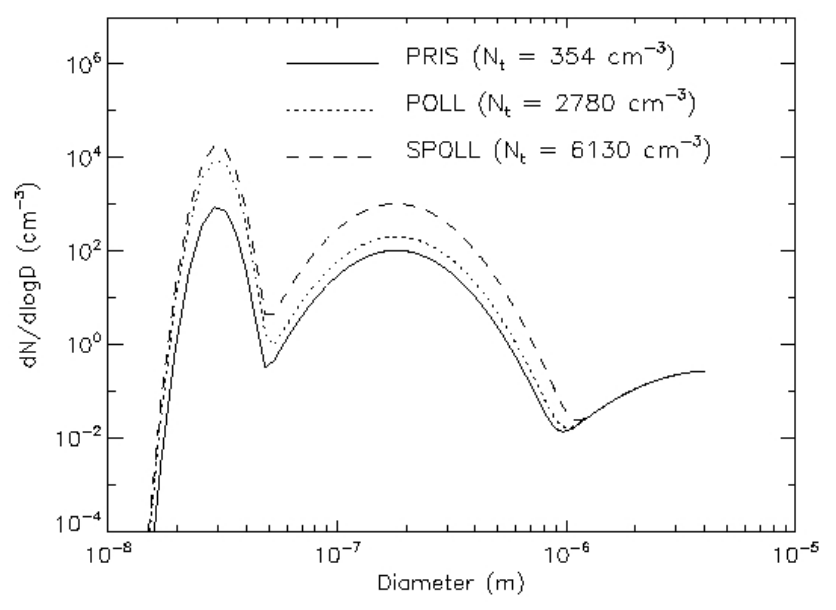

Fig. 1. Specified background aerosol size distributions for the pristine (PRIS), polluted (POLL), and highly polluted (SPOLL) simulations.

in surprisingly large changes in TOA radiative fluxes, even when averaged over the six day focus period. These tests demonstrate large variability resulting from different realizations. Fundamentally, this variability and low level of predictability is associated with inherent randomness in the timing, location, and intensity of individual deep convective events. Issues related to the predictability of moist deep convection in a cloud-system scale (convection permitting) model have been previously explored by Zhang et al. (2007), and predictability and solution drift among different realizations using models with parameterized convection has been described by Hack and Pedretti (2000) and Tan et al. (2004).

To more systematically analyze this variability, we ran a large member ensemble (240) using pristine aerosol conditions. Different members were generated using a different seed to initiate the small random perturbations applied to the low-level $\theta$ (see Sect. 3). Timeseries of TOA outgoing longwave radiation (OLR) and reflected shortwave radiation (RSW) for the three ensemble members with the largest timemean OLR and three with the smallest time-mean OLR are shown in Fig. 2 to illustrate the overall ensemble spread; time-mean OLR and RSW for these six runs are shown in Table 1. In general, simulations with larger OLR tend to have smaller RSW, which is expected given the approximate cancellation of longwave and shortwave cloud forcing for deep clouds. While there are large differences in time-mean OLR and RSW, most of these differences occur after about 16:00 UTC 23 January. This time corresponds with the most intense convection and hence lowest OLR.

To better understand differences between realizations, we analyze budgets of water vapor mixing ratio, $q$, dry static energy, $s=c_{\mathrm{p}} T+\phi$ ( $T$ is temperature, $c_{\mathrm{p}}$ is specific heat of air at constant pressure, and $\phi$ is geopotential), and moist static energy, $h=s+L_{\mathrm{v}} q\left(L_{\mathrm{v}}\right.$ is the latent heat of vaporization).

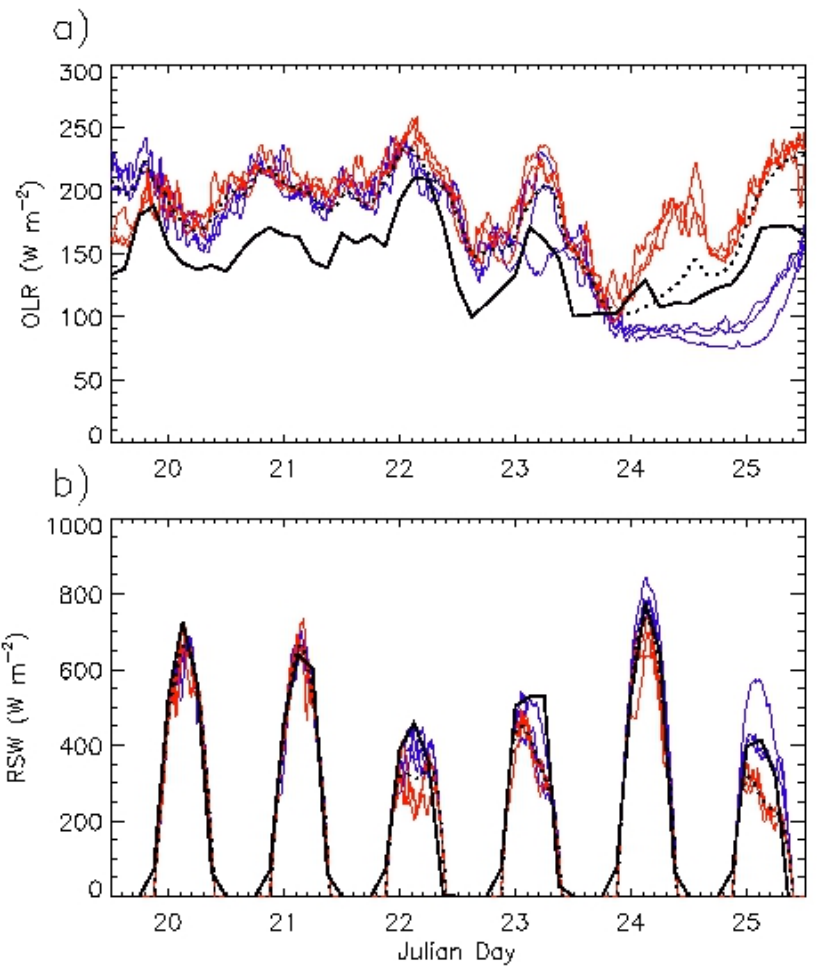

Fig. 2. Timeseries of horizontally-averaged TOA (a) outgoing longwave radiation (OLR) and (b) reflected shortwave radiation (RSW) for the three low-OLR (blue) and three high-OLR (red) realizations. Observations are indicated by the solid black lines, and the ensemble-mean OLR and RSW are indicated by the dotted black lines.

Conservation equations for horizontally-averaged $q, s$, and $h$ are given by

$$
\begin{aligned}
& \frac{\partial \bar{q}}{\partial t}+\nabla \cdot(\bar{q} \bar{V})+\frac{\partial(\bar{q} \bar{\omega})}{\partial p}+\frac{\partial\left(\overline{q^{\prime} \omega^{\prime}}\right)}{\partial p}=S_{q} \\
& \frac{\partial \bar{s}}{\partial t}+\nabla \cdot(\bar{s} \bar{V})+\frac{\partial(\bar{s} \bar{\omega})}{\partial p}+\frac{\partial\left(\overline{s^{\prime} \omega^{\prime}}\right)}{\partial p}=S_{s} \\
& \frac{\partial \bar{h}}{\partial t}+\nabla \cdot(\bar{h} \bar{V})+\frac{\partial(\bar{h} \bar{\omega})}{\partial p}+\frac{\partial\left(\overline{h^{\prime} \omega^{\prime}}\right)}{\partial p}=S_{h}
\end{aligned}
$$

where $t$ is time, $\omega$ is the vertical pressure velocity, the second terms on the left-hand-side (1.h.s.) of Eqs. (1-3) are the specified large-scale horizontal advection, the third terms on the l.h.s. are the specified large-scale vertical advection, the fourth terms on the 1.h.s. are the resolved and subgrid-scale vertical flux divergence, and the terms on the right-handside (r.h.s.) are the sources and sinks due to microphysical processes, latent heating, and/or radiative flux convergence. Overbars denote horizontal average and primes denote deviation from the horizontal-average. Hereafter, quantities are horizontally-averaged unless stated otherwise, and overbars will be omitted. Note that for the model prognostic variables, 
Table 1. OLR, RSW, and terms in the vertically-integrated $s, q$, and $h$ budgets from Eqs. (4-6) for the three low-OLR (L1, L2, L3) and three high-OLR (H1, H2, H3) ensemble members with pristine aerosols. Presented quantities are averaged between 12:00 UTC 19 January and 12:00 UTC 25 January. DIV $(s)$, DIV $\left(L_{\mathrm{V}} q\right)$, and DIV $(h)$ are the vertically-integrated imposed large-scale 3-D advection of $s, L_{\mathrm{v}} q$, and $h$, and are identical in all simulations. Units are $\mathrm{W} \mathrm{m}^{-2}$.

\begin{tabular}{|c|c|c|c|c|c|c|c|c|c|c|c|c|}
\hline Run & OLR & RSW & $F_{\mathrm{L}}$ & $F_{S}$ & $F_{\mathrm{R}}$ & $F_{\mathrm{P}}$ & $\frac{\partial\langle s\rangle}{\partial t}$ & $\frac{\partial\left\langle L_{\mathrm{V}} q\right\rangle}{\partial t}$ & $\frac{\partial\langle h\rangle}{\partial t}$ & $\operatorname{DIV}(s)$ & $\operatorname{DIV}\left(L_{\mathrm{v}} q\right)$ & DIV $(h)$ \\
\hline L1 & 160.8 & 212.6 & 177.1 & 10.5 & -29.6 & 805.5 & 11.0 & -24.5 & -13.5 & 780.9 & -599.3 & 181.6 \\
\hline $\mathrm{L} 2$ & 161.1 & 203.3 & 177.2 & 10.7 & -28.7 & 814.5 & 17.5 & -30.3 & -12.7 & ” & $"$ & " \\
\hline L3 & 161.7 & 201.2 & 179.5 & 10.8 & -29.6 & 814.2 & 13.5 & -24.8 & -11.2 & $"$ & $"$ & " \\
\hline $\mathrm{H} 1$ & 188.4 & 183.6 & 171.5 & 9.5 & -53.5 & 802.4 & -17.1 & -25.4 & -42.6 & $"$ & $"$ & " \\
\hline $\mathrm{H} 2$ & 187.3 & 179.3 & 173.3 & 10.2 & -51.7 & 803.6 & -6.1 & -32.6 & -38.9 & " & $"$ & $"$ \\
\hline $\mathrm{H} 3$ & 186.8 & 180.5 & 187.8 & 11.8 & -52.6 & 804.8 & -10.6 & -13.1 & -23.7 & $"$ & $"$ & $"$ \\
\hline
\end{tabular}

both large-scale horizontal and vertical advective forcings of $\theta$ and $q$ are specified (see Sect. 3). Nonzero large-scale vertical velocity (and thus vertical advection) is inconsistent with periodic lateral boundary conditions (see discussion in Grabowski et al., 1996), but is applied here since it represents a key component of the large-scale forcing.

Assuming that $\omega=\omega^{\prime}=0$ at the surface and top of the troposphere, Eqs. (1-3) may be vertically-integrated over the depth of the troposphere to give

$$
\begin{aligned}
& \frac{\partial\left\langle L_{\mathrm{v}} q\right\rangle}{\partial t}+\left\langle\nabla \cdot\left(L_{\mathrm{v}} q V\right)\right\rangle \approx F_{\mathrm{L}}-F_{\mathrm{P}} \\
& \frac{\partial\langle s\rangle}{\partial t}+\langle\nabla \cdot(s V)\rangle \approx F_{\mathrm{S}}+F_{\mathrm{P}}+F_{\mathrm{R}} \\
& \frac{\partial\langle h\rangle}{\partial t}+\langle\nabla \cdot(h V)\rangle \approx F_{\mathrm{L}}+F_{\mathrm{S}}+F_{\mathrm{R}}
\end{aligned}
$$

where the operator \langle\rangle indicates density-weighted vertical integration over the depth of the troposphere (i.e. $\langle x\rangle=$ $\int_{p_{\mathrm{s}}}^{p_{\mathrm{s}}} x d p / g$, where $p_{\mathrm{s}}$ and $p_{\mathrm{t}}$ are surface and tropopause pressures and $g$ is gravitational acceleration) and $F_{\mathrm{P}}, F_{\mathrm{L}}$, and $F_{\mathrm{S}}$ are the surface fluxes of precipitation (in energy units), latent heat, and sensible heat, and $F_{\mathrm{R}}$ is the radiative flux convergence of the troposphere (i.e. net surface flux minus net flux at TOA, which is assumed to be equal to the net flux at the tropopause). Positive values indicate a net flux into the troposphere. Note that Eqs. (4-6) are only approximate since they assume that net condensation in the column (total condensation minus evaporation) is instantly removed as surface precipitation; this assumption is reasonable for the 6-day period analyzed here. For simplicity we neglect the energy associated with phase transformations involving ice since precipitation at the surface is almost entirely liquid. Thus, the ice phase redistributes static energy in the vertical but does not impact column-integrated and time-averaged budgets, except for ice condensate that remains in the atmosphere at the end of the simulations (which again has minimal contributions to the energy budgets over the 6-day period analyzed).
Timeseries of the $\left\langle L_{\mathrm{v}} q\right\rangle,\langle s\rangle$, and $\langle h\rangle$ budget terms in Eqs. (4-6) for the three low-OLR and three high-OLR runs are shown in Figs. 3-5, with time-averaged values shown in Table 1. There is reasonable agreement between the model and observations for most quantities (Fig. 5), especially $F_{\mathrm{P}}$ which is highly constrained by the specified large-scale forcing as described below. Differences between the simulated and observed $F_{\mathrm{S}}$ and $F_{\mathrm{L}}$ likely reflect the assumption of an ocean surface in the model, while the observations are based on a combination of land and ocean sites (Xie et al., 2010). Differences between the modeled and observed surface heat fluxes have a limited impact on the timing and amplitude of $F_{\mathrm{P}}$, given its constraint by the applied large-scale forcing of $s$ and $q$. Similarly, differences in $F_{\mathrm{R}}$, and the bias in the longwave component of $F_{\mathrm{r}}$ in particular, likely result from the assumption of an ocean surface with fixed SST in the model while observations are derived from satellite which includes areas over both land and ocean. Simulated OLR and RSW, which are somewhat less dependent than the longwave and shortwave components of $F_{\mathrm{R}}$ on surface conditions, are fairly close to observations (Fig. 2). These results indicate general realism of the simulations; a more detailed comparison of model results with observations including microphysical quantities is provided by Fridlind et al. (2011). Detailed comparison of model simulations and observations using a radar simulator for TWP-ICE will also be the focus of a future paper.

The radiative flux convergence, $F_{\mathrm{R}}$, is somewhat larger in the low-OLR than high-OLR ensemble members, consistent with enhanced upper-tropospheric radiative heating associated with thicker and higher anvil cirrus as described below. However, these differences are small compared with the magnitude of other budget terms such as surface latent heat flux, $F_{\mathrm{L}}$, and surface precipitation, $F_{\mathrm{P}}$. There are no consistent differences in $F_{\mathrm{L}}$ and surface sensible heat flux, $F_{\mathrm{H}}$, among ensemble members (Fig. 5a, b), which is consistent with little difference in time-mean low-level $T$ and relative humidity, RH, (Fig. 6), or the low-level wind field (which is nudged to observations, see Sect. 3). Ensemble distributions 

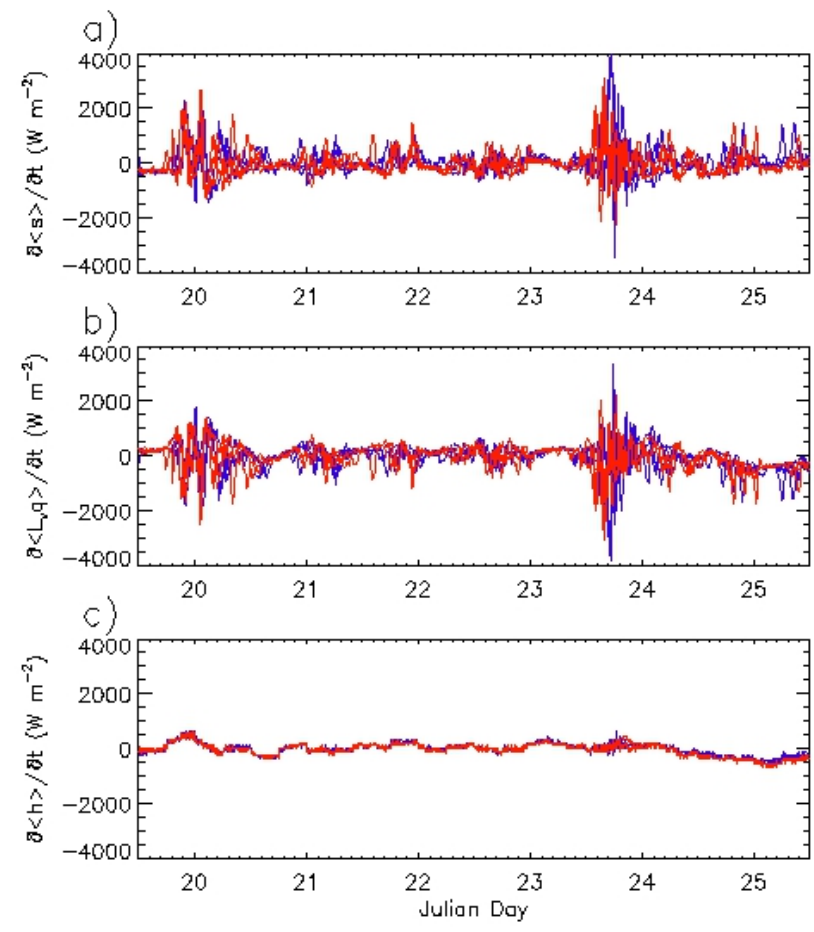

Fig. 3. As in Fig. 2, except timeseries of horizontally-averaged vertically-integrated time tendencies: (a) $\frac{\partial\langle s\rangle}{\partial t}$, (b) $\frac{\partial\left\langle L_{\mathrm{v}} q\right\rangle}{\partial t}$, and (c) $\frac{\partial\langle h\rangle}{\partial t}$.

of the time-mean quantities shown in Figs. 2, 3, and 5 are fairly unskewed and reasonably approximated as Gaussian (not shown).

While there is noisiness and occasionally large values of $\frac{\partial\langle s\rangle}{\partial t}$ and $\frac{\partial\left\langle L_{\mathrm{v}} q\right\rangle}{\partial t}$ as seen in Fig. 3, which corresponds with the timing of individual deep convective events, temporal averaging over periods of $6-12 \mathrm{~h}$ or longer eliminates most noise. At a given time there is substantial ensemble variability of $\frac{\partial\langle s\rangle}{\partial t}$ and $\frac{\partial\left\langle L_{\mathrm{v}} q\right\rangle}{\partial t}$, but these differences are also greatly reduced with temporal averaging. Limited time-averaged ensemble variability of $\frac{\partial\langle s\rangle}{\partial t}, \frac{\partial\left\langle L_{\mathrm{v}} q\right\rangle}{\partial t}$, and other terms in Eqs. (46 ) is consistent with previous 2-D CSRM studies (Grabowski et al., 1999; Khairoutdinov and Randall, 2003). Noisiness is largely absent in the timeseries of $\frac{\partial\langle h\rangle}{\partial t}$ (Fig. 3c) since $h$ is approximately conserved during moist convection. The large-scale divergence $\langle\nabla \cdot(s V)\rangle$ is mostly positive (Fig. 4a) and largely balances diabatic heating, while $\left\langle\nabla \cdot\left(L_{\mathrm{v}} q V\right)\right\rangle$ is mostly negative (Fig. 4b) and balances surface precipitation. Large-scale advection/divergence of $q$ and $s$ are generally opposite in sign; thus, they largely cancel and as a result $\langle\nabla \cdot(h V)\rangle$ is fairly small (Fig. 4c). A relatively constant $\langle s\rangle$ maintained by large-scale forcing, despite large diabatic heating rates, is analogous to the weak temperature gradient (WTG) assumption (e.g. Raymond, 2000; Sobel and Bretherton, 2000). This is a good approximation in equatorial regions given rapid dispersal of buoyancy anomalies by gravity waves in the absence of a significant Coriolis acceleration.

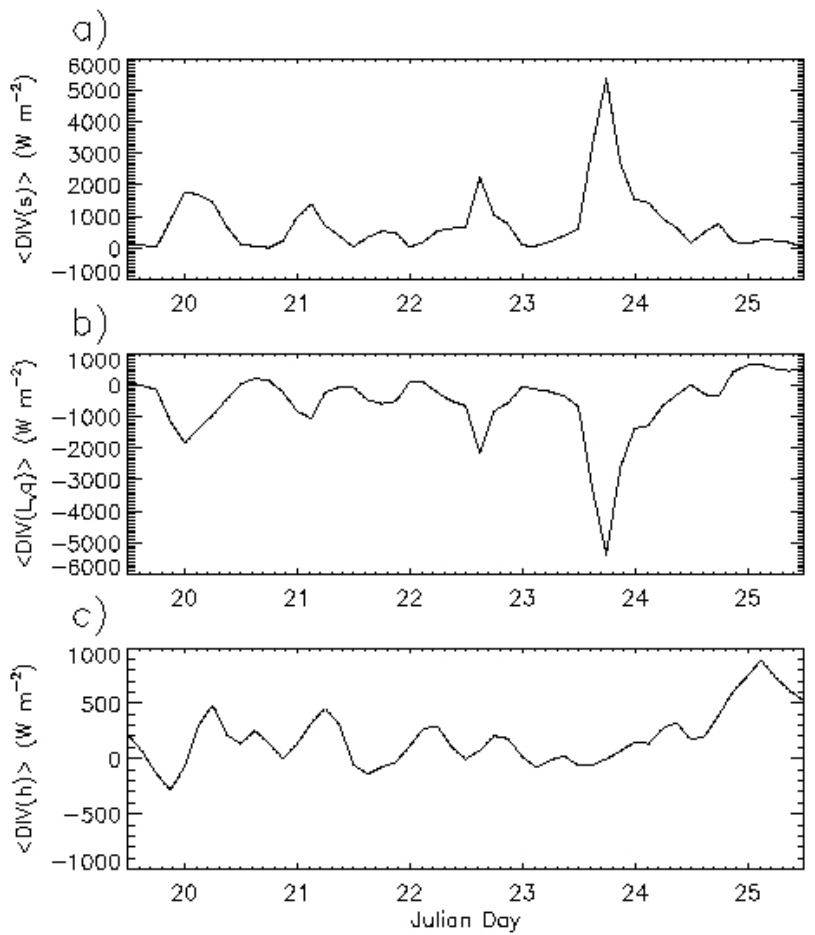

Fig. 4. Timeseries of the specified vertically-integrated large-scale 3D advection: (a) $\langle\nabla \cdot(s V)\rangle$, (b) $\left\langle\nabla \cdot\left(L_{\mathrm{v}} q V\right)\right\rangle$, and (c) $\langle\nabla \cdot(h V)\rangle$.

The tendency of the tropical atmosphere to precipitate is strongly linked to the column saturation fraction, $S=\frac{\langle q\rangle}{\left\langle q_{s}\right\rangle}$ where $q_{s}$ is the saturation mixing ratio. Several observational and modeling studies have shown that as values of $S$ increase above $\sim 0.75$, precipitation rapidly increases (e.g. Raymond, 2000; Bretherton et al., 2004; Back and Bretherton, 2005; Peters and Neelin, 2006; Raymond et al., 2007). In conjunction with relatively constant column dry static energy $\langle s\rangle$, any additional vapor convergence due to large-scale forcing or $F_{\mathrm{L}}$ is rapidly removed as precipitation for values of $S \sim 0.8$ to 0.9 , without further increasing $S$. Timeseries of $S$ for the three high-OLR and three low-OLR runs indeed show relatively constant values of $S$ between 0.8 and 0.9 despite large moistening rates from the applied large-scale vapor convergence, except for slight drying on 25 January (Fig. 7). This limit provides a "stiff" constraint on both $S$ and surface precipitation (Raymond et al., 2009). This picture is consistent with a $\left\langle L_{\mathrm{v}} q\right\rangle$ budget that mostly represents a balance between $\left\langle\nabla \cdot\left(L_{\mathrm{v}} q V\right)\right\rangle$ and $F_{\mathrm{P}}$, with a smaller contribution from $F_{\mathrm{L}}$ (Figs. 3d, 4b, Table 1). As a result of this constraint, surface precipitation varies little among the ensemble members, and, as shown in Sect. 5, also exhibits little sensitivity to aerosols.

Vertical profiles of horizontally-averaged updraft mass flux, $M_{\mathrm{u}}$, also vary little between ensemble members (Fig. 8a). There are no consistent differences in updraft mass flux conditionally-averaged over areas with convective updrafts, $M_{\mathrm{c}}$, between the low-OLR and high-OLR runs 

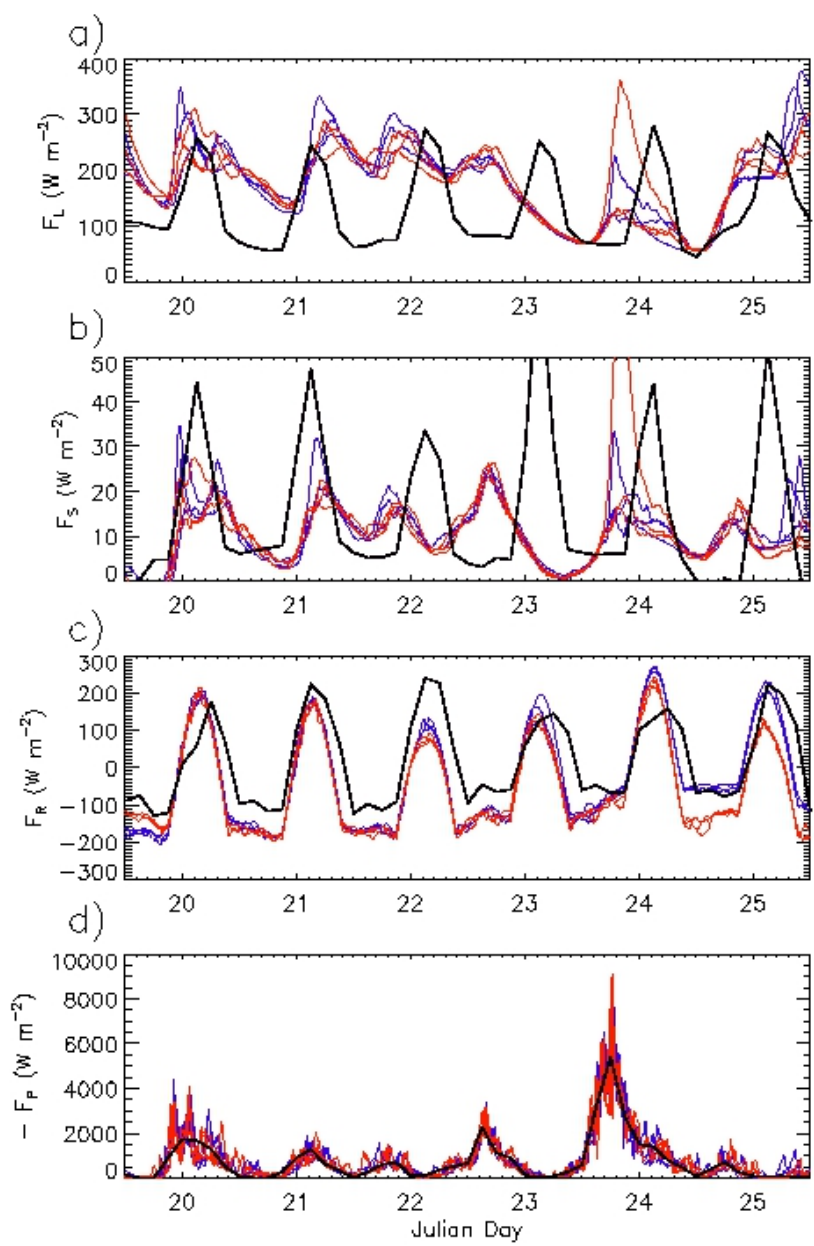

Fig. 5. As in Fig. 2, except timeseries of horizontally-averaged (a) surface latent heat flux, $F_{\mathrm{L}}$, (b) surface sensible heat flux, $F_{\mathrm{S}}$, (c) atmospheric radiative flux convergence, $F_{\mathrm{R}}$, and (d) surface precipitation, $F_{\mathrm{P}}$. Observed values are indicated by black lines.

(Fig. 8c), although the fractional area of updrafts, $F_{\mathrm{c}}$, tends to be somewhat larger in the low-OLR runs, especially near $200 \mathrm{hPa}$ (Fig. 8b) (here convective updrafts are defined using a threshold vertical velocity, $w$, of $1 \mathrm{~m} \mathrm{~s}^{-1}$ ). This implies that in the low-OLR runs, somewhat more total updraft mass flux is carried by convective drafts with $w>1 \mathrm{~m} \mathrm{~s}^{-1}$ compared to the high-OLR runs.

Unlike surface precipitation, OLR and RSW are not subject to stiff constraints related to $S$ or other quantities. Low values of OLR in the three runs with smallest time-mean OLR are clearly associated with greater anvil height and ice mixing ratio, $q_{\mathrm{i}}$, as indicated by time- and domain-mean vertical profiles of cloud microphysical quantities (Fig. 9). Values of $q_{\mathrm{i}}$ and ice number concentration, $N_{\mathrm{i}}$, are much larger above $200 \mathrm{hPa}$ in the low-OLR compared to the high-OLR ensemble members, resulting in greater emissivity and optical depth. Other microphysical quantities (cloud water mixing ratio and number concentration, $q_{\mathrm{c}}$ and $N_{\mathrm{c}}$, respectively,

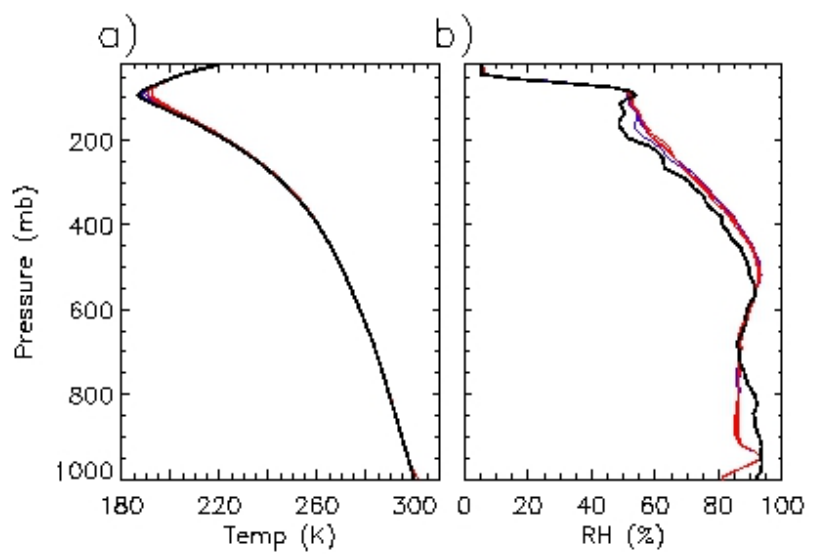

Fig. 6. Horizontally-averaged profiles of (a) temperature and (b) RH for the three low-OLR realizations (blue) and the three highOLR realizations (red) averaged between 12;00 UTC 19 January to 12:00 UTC 25 January. Observations are shown by the black line.

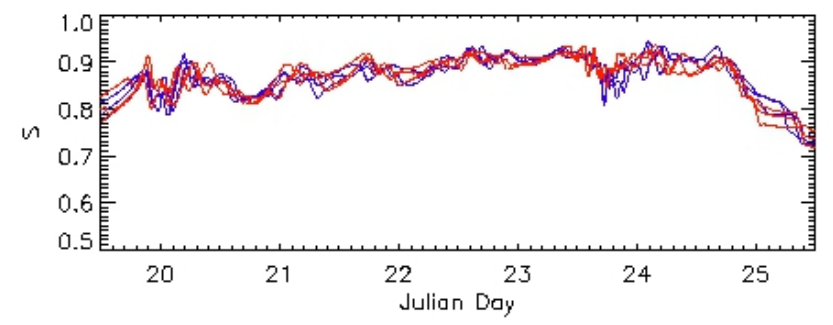

Fig. 7. As in Fig. 2, except for timeseries of the horizontallyaverage column saturation fraction.

and rain mixing ratio and number concentration, $q_{\mathrm{r}}$ and $N_{\mathrm{r}}$, respectively) are nearly identical between ensemble members.

What drives large differences in upper tropospheric ice in different realizations? Although there is overall similarity in the convective characteristics between the ensemble members, there is somewhat larger convective updraft fraction, $F_{\mathrm{c}}$, and mean convective updraft mass flux, $F_{\mathrm{c}} M_{\mathrm{c}}$, near the $200 \mathrm{hPa}$ level in the low-OLR compared to the high-OLR runs (Fig. 8b, c). Larger $F_{\mathrm{c}}$ at this level leads to a larger upward flux of $N_{\mathrm{c}}$; these droplets subsequently freeze rapidly when exposed to colder conditions. This contributes to larger $N_{\mathrm{i}}$, smaller particle size, and reduced ice sedimentation flux in the anvil; in conjunction with greater detrainment of condensate this leads to greater $q_{\mathrm{i}}$ near the tropopause. Larger $N_{\mathrm{i}}$ also leads to smaller values of ice effective radius, $r_{\mathrm{ei}}$ (not shown), which is broadly consistent with satellite retrievals suggesting a decrease of $r_{\mathrm{ei}}$ with increasing convective strength (Sherwood et al., 2002). Time-averaged temperatures near the tropopause are $1-2 \mathrm{~K}$ lower in the lowOLR runs (Fig. 6a), despite having radiative heating rates that are up to $7.5 \mathrm{~K} \mathrm{day}^{-1}$ larger compared to the high-OLR runs (Fig. 8d). 
Table 2. Ensemble means of OLR, RSW, and terms in the vertically-integrated $s, q$, and $h$ budgets for PRIS, POLL, and SPOLL. Ensemble standard deviations are shown in parentheses. Presented quantities are averaged from 12:00 UTC 19 January to 12:00 UTC 25 January. Units are $\mathrm{W} \mathrm{m}^{-2}$.

\begin{tabular}{lrrrrrrrrr}
\hline & OLR & RSW & $F_{\mathrm{L}}$ & $F_{S}$ & $F_{\mathrm{R}}$ & $F_{\mathrm{P}}$ & $\frac{\partial\langle s\rangle}{\partial t}$ & $\frac{\partial\left\langle L_{\mathrm{v}} q\right\rangle}{\partial t}$ & $\frac{\partial\langle h\rangle}{\partial t}$ \\
\hline PRIS & $177.3(4.9)$ & $189.2(4.3)$ & $176.3(5.2)$ & $10.4(0.7)$ & $-43.7(4.4)$ & $807.2(7.8)$ & $1.4(7.8)$ & $-29.9(6.6)$ & $-28.4(6.9)$ \\
POLL & $166.7(7.0)$ & $199.9(6.6)$ & $174.6(5.6)$ & $9.9(0.7)$ & $-34.6(6.4)$ & $804.0(8.2)$ & $5.5(8.2)$ & $-26.9(6.5)$ & $-21.3(8.2)$ \\
SPOLL & $163.9(6.4)$ & $208.2(7.7)$ & $174.3(5.2)$ & $9.6(0.7)$ & $-32.2(5.8)$ & $803.5(8.8)$ & $6.1(8.8)$ & $-25.8(6.3)$ & $-19.6(8.0)$ \\
\hline
\end{tabular}
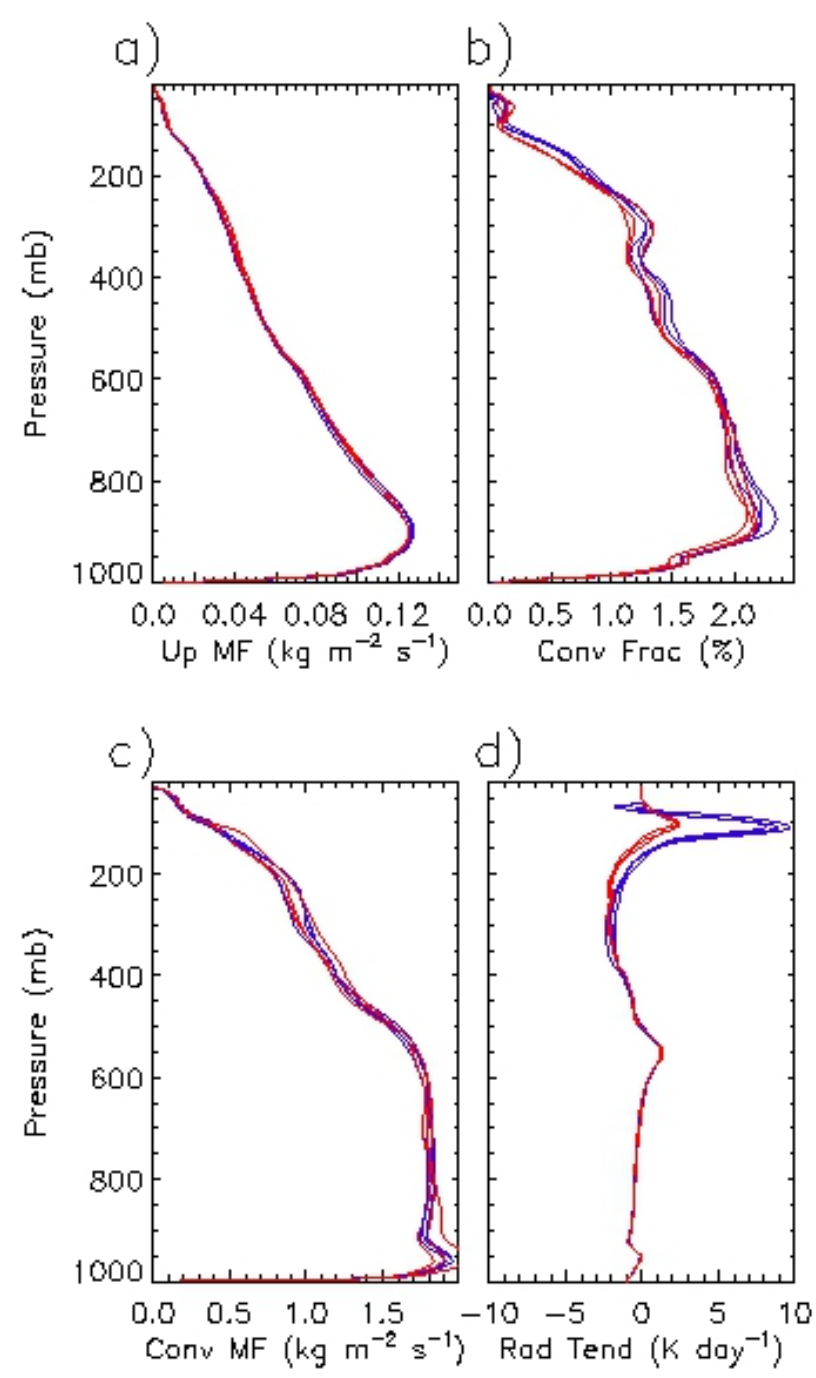

Fig. 8. As in Fig. 6, except for vertical profiles of (a) updraft mass flux, (b) fraction of the domain containing convective updrafts, (c) convective updraft mass flux averaged over cells containing convective updrafts, and (d) temperature tendency due to radiative heating.

Note that there is a negative feedback on the strength of convection because enhanced tropopause ice in the runs with larger $F_{\mathrm{c}}$ near $200 \mathrm{hPa}$ leads to greater radiative heating in upper troposphere (Fig. 8d) and hence stabilization of the troposphere, which one might expect would lead to a decrease in convective strength (Fowler and Randall, 1994; Stephens et al., 2008). For the ensemble means with different aerosol loadings, there is indeed a close relationship between increased upper-tropospheric radiative heating and weaker convection (see Sect. 5). However, for a given realization, random fluctuations in the strength of convection can lead to stronger convection when averaged in time despite increased upper-tropospheric radiative heating and tropospheric stabilization. This randomness gets averaged out when analyzing the ensemble means.

\section{Comparison of pristine and polluted simulations}

Given the large variability of OLR and RSW for different realizations using the same aerosol conditions, we use the ensemble approach (240 members each) for PRIS, POLL, and SPOLL in order to determine a statistically significant aerosol indirect effect. For an ensemble standard deviation of $6 \mathrm{~W} \mathrm{~m}^{-2}$ for OLR and $\mathrm{RSW}$, which is a typical value for the different model configurations and aerosol conditions as shown later, this ensemble size provides statistical significance at the $95 \%$ confidence level for an aerosol indirect effect as small as $\sim 1 \mathrm{~W} \mathrm{~m}^{-2}$, based on Student's t test. For actual significance testing described herein we employ the Welch-Satterthwaite approach (Satterthwaite, 1946; Welch, 1947) to account for possible differences in variance between ensembles. Hereafter statistical significance will refer to significance at the $95 \%$ confidence level.

Not surprisingly, timeseries of ensemble-mean $\frac{\partial\langle s\rangle}{\partial t}$, $\frac{\partial\left\langle L_{\mathrm{v}} q\right\rangle}{\partial t}$, and $\frac{\partial\langle h\rangle}{\partial t}$ for PRIS, POLL, and SPOLL (Fig. 10) are much less noisy than in any single realization (cf. Fig. 3). Differences in these quantities between PRIS, POLL, and SPOLL are small (Fig. 10, Table 2). Differences in the $s$, $q$, and $h$ forcing terms on the r.h.s. of Eqs. (4-6) for the ensemble-mean PRIS, POLL, and SPOLL are also generally small (Fig. 11, Table 2). However, there is a significant increase in $F_{\mathrm{R}}$ due to larger upper-tropospheric radiative heating rates in POLL and SPOLL. There is a statisticallysignificant decrease of precipitation with increased aerosol, but differences in the ensemble-mean $F_{\mathrm{P}}$ between PRIS, 


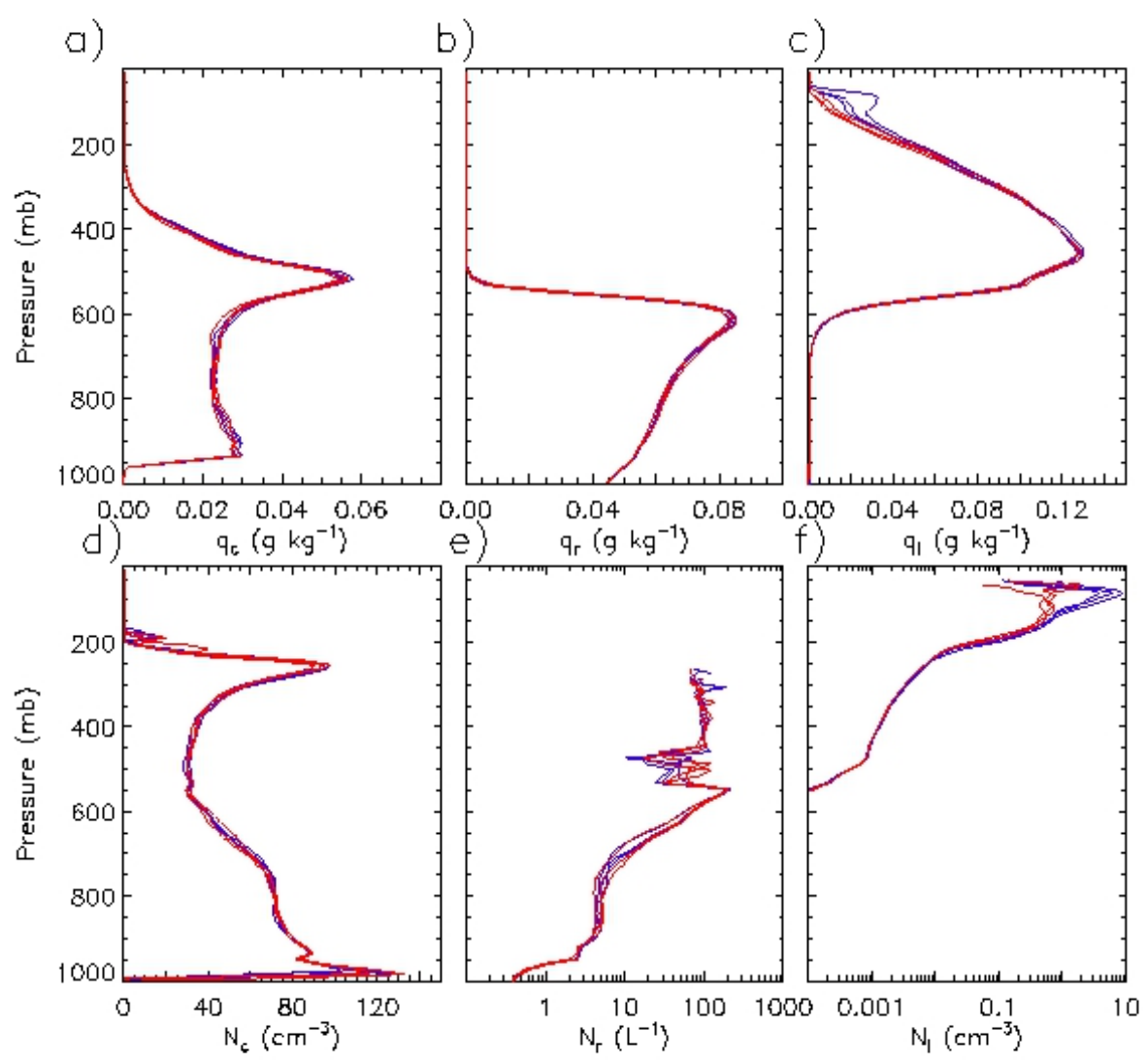

Fig. 9. As in Fig. 6, except for profiles of horizontally-averaged (a) cloud water mixing ratio, $q_{\mathrm{c}}$, (b) rain mixing ratio, $q_{\mathrm{r}}$, (c) ice mixing ratio, $q_{\mathrm{i}}$, (d) cloud droplet concentration, $N_{\mathrm{c}}$, (e) rain number concentration, $N_{\mathrm{r}}$, and (f) ice number concentration, $N_{\mathrm{i}}$. Presented results are averaged between 12:00 UTC 19 January to 12:00 UTC 25 January. Number concentrations are averaged over grid cells with mixing ratio greater than $0.001 \mathrm{~g} \mathrm{~kg}^{-1}$ for the given hydrometeor species.

POLL, and SPOLL are very small $(<0.5 \%)$. Thus, aerosols have little impact on time- and domain-mean surface precipitation in these simulations, which is consistent with the stiff constraint on precipitation discussed in Sect. 4. There is also a statistically-significant decrease in ensemble-mean $F_{\mathrm{L}}$, but the differences are also very small $(<1.1 \%)$.

There are much larger (statistically-significant) differences in OLR and RSW with increased aerosol loading compared to surface precipitation and the other budget terms in Eqs. (46) (Fig. 12, Table 2). Increased aerosol loading in POLL and SPOLL leads to consistently larger ensemble-mean RSW and smaller OLR, especially during and after the period of intense convection and heavy precipitation on 23 and 24 January (Fig. 12). In terms of time-mean values, the differences in ensemble-mean OLR are +10.6 (POLL minus PRIS) and +13.4 (SPOLL minus PRIS) $\mathrm{W} \mathrm{m}^{-2}$. For RSW, the differences are -10.7 and $-19.0 \mathrm{~W} \mathrm{~m}^{-2}$, respectively. The aerosol impacts on OLR and RSW largely cancel for POLL minus PRIS, while for SPOLL minus PRIS there is a somewhat larger shortwave effect that results in a net change in the TOA energy balance of $-5.6 \mathrm{~W} \mathrm{~m}^{-2}$.
The impact of aerosols on time-mean and ensemble-mean microphysical profiles is shown in Fig. 13. Results are largely as expected. With increased aerosol loading in POLL and SPOLL, there is a large increase in $N_{\mathrm{c}}$ and subsequent increase in $q_{\mathrm{c}}$ of roughly $30 \%$ due to reduced collisioncoalescence. Note that the decrease of $N_{\mathrm{c}}$ with height seen in Fig. $13 \mathrm{~d}$ is likely due to the impact of mixing and dilution in weak updrafts; $N_{\mathrm{c}}$ is relatively constant with height when averaged only in convective updrafts $\left(w>1 \mathrm{~m} \mathrm{~s}^{-1}\right.$ ) (not shown). In convective updrafts, the average $N_{\mathrm{c}}$ are roughly 2 and 5 times greater in POLL and SPOLL than PRIS, respectively, but with a lower activated fraction (i.e. ratio of cloud droplet and total background aerosol concentrations). The increase of $N_{\mathrm{c}}$ above $400 \mathrm{hPa}$ in Fig. 13d is because liquid water tends to occur only in strong updrafts at these levels, resulting in greater $N_{\mathrm{c}}$ when conditionally-averaged over locations containing liquid water $\left(q_{\mathrm{c}}>0.001 \mathrm{gkg}^{-1}\right)$. With reduced collision-coalescence there is also a decrease in $q_{\mathrm{r}}$ and especially $N_{\mathrm{r}}$ in POLL and SPOLL. However, values of $q_{\mathrm{r}}$ and $N_{\mathrm{r}}$ near the surface are almost identical, which is consistent with the insensitivity of surface precipitation to aerosols. This result reflects the compensation of 

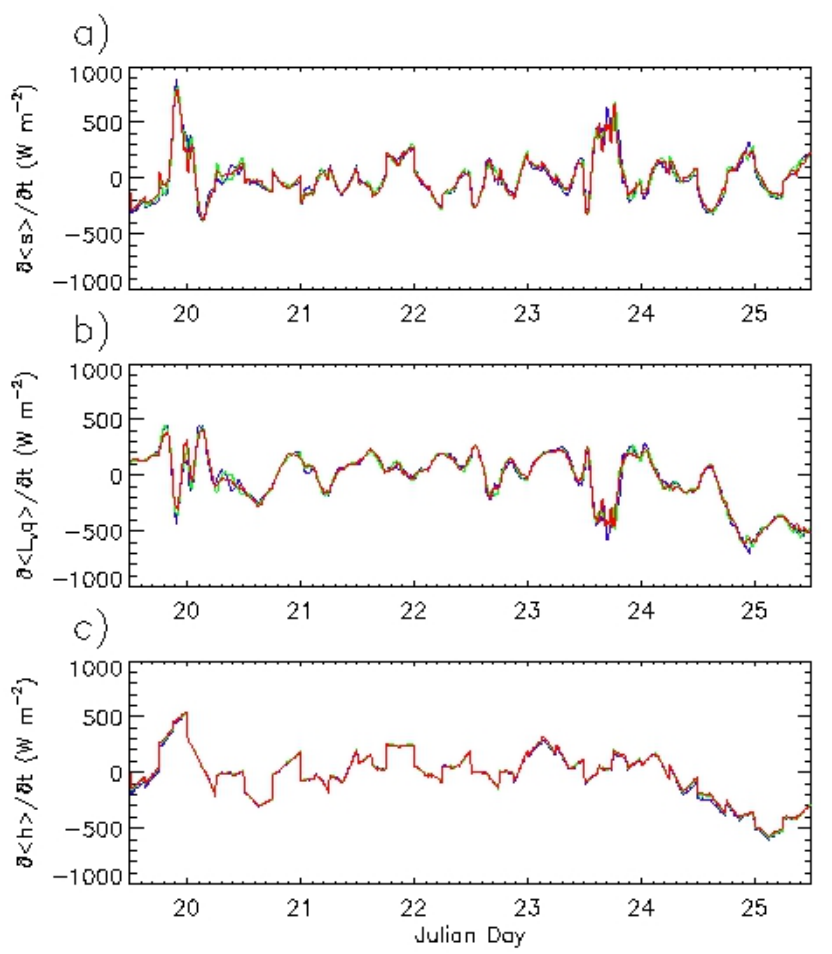

Fig. 10. Timeseries of ensemble- and horizontally-averaged and vertically-integrated time tendencies: (a) $\frac{\partial\langle s\rangle}{\partial t}$, (b) $\frac{\partial\left\langle L_{\mathrm{v}} q\right\rangle}{\partial t}$, and (c) $\frac{\partial\langle h\rangle}{\partial t}$ for PRIS (blue), POLL (green), and SPOLL (red).

microphysical processes (for example, there is decreased rain evaporation with a reduction of $q_{\mathrm{r}}$ and $N_{\mathrm{r}}$ ) similar to the findings of Grabowski (2006), Slawinska et al. (2009), and Grabowski and Morrison (2011).

Ice microphysical quantities are also impacted by aerosols, primarily above $300 \mathrm{hPa}$. There is an increase of $N_{\mathrm{i}}$ in POLL and SPOLL at most levels (Fig. 13f), and a large increase in $q_{\mathrm{i}}$ above $150 \mathrm{hPa}$ but a small reduction below this level (resulting in a higher cloud top) (Fig. 13c). These differences explain almost all of the decrease in ensemble-mean OLR with aerosol loading; differences in RSW are mostly due to changes in the liquid microphysics alone as discussed further below.

The key question, then, is what drives higher cloud (anvil) top and greater $q_{\mathrm{i}}$ near the tropopause in polluted conditions? One might guess that this result is due to invigoration of convection as suggested by Rosenfeld et al. (2008) and others, especially since larger $F_{\mathrm{c}}$ appeared to be responsible for greater anvil height and $q_{\mathrm{i}}$ in the low-OLR compared to high-OLR realizations using pristine aerosol (see Sect. 4). However, it is clear from time- and ensemble-mean profiles of $M_{\mathrm{u}}, F_{\mathrm{c}}$, and $M_{\mathrm{c}}$ that convection is actually slightly weaker in the polluted ensembles, especially above $500 \mathrm{hPa}$ (Fig. 14). There is slightly reduced $M_{\mathrm{u}}$ in POLL and SPOLL compared to PRIS (Fig. 14a), but a much larger relative re-
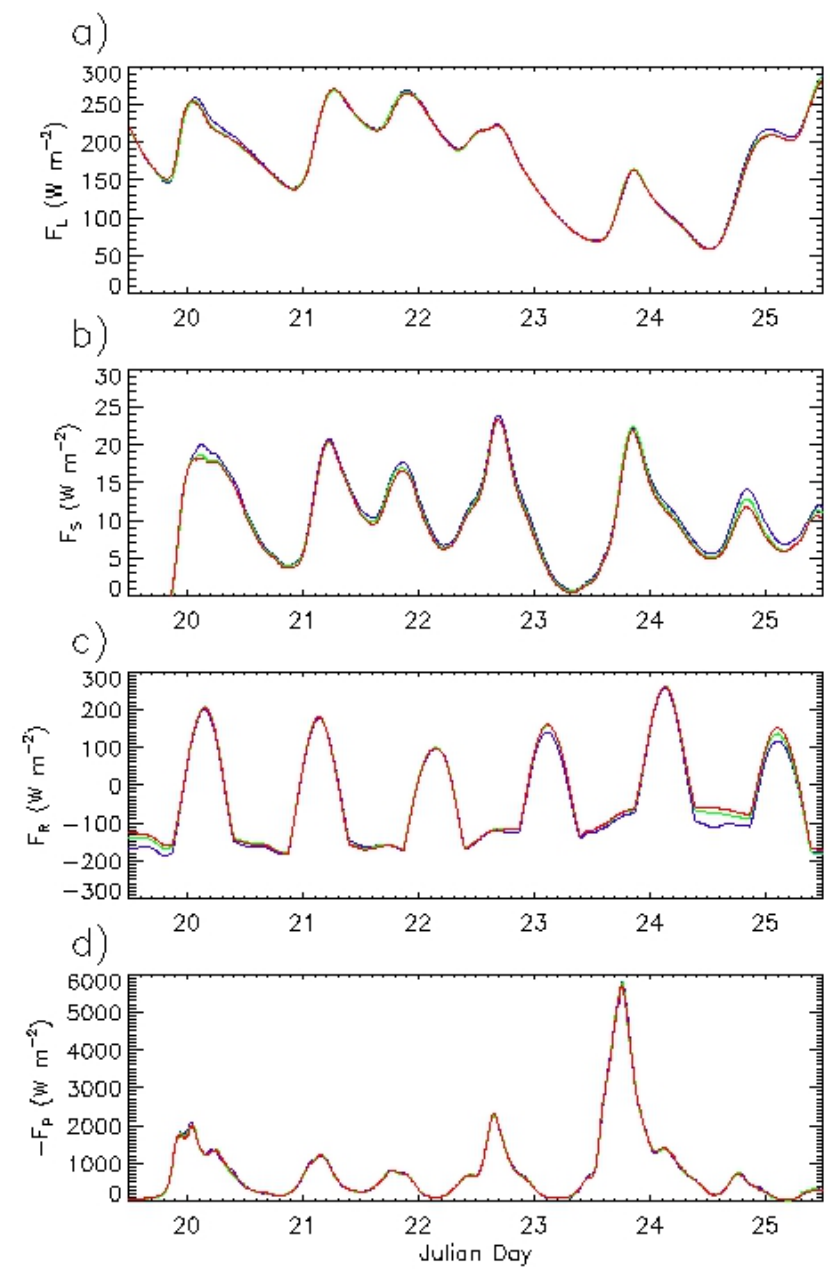

Fig. 11. Timeseries of ensemble- and horizontally-averaged (a) surface latent heat flux, $F_{\mathrm{L}}$, (b) surface sensible heat flux, $F_{\mathrm{S}}$, (c) atmospheric radiative flux convergence, $F_{\mathrm{R}}$, and (d) surface precipitation, $F_{\mathrm{P}}$, for PRIS (blue), POLL (green), and SPOLL (red).

duction in $F_{\mathrm{c}}$ (Fig. 14b). Histograms of vertical velocity at various heights (not shown) also indicate a lower frequency of occurrence over a range of convective vertical velocities $\left(1<w<10 \mathrm{~m} \mathrm{~s}^{-1}\right)$ in polluted compared to pristine conditions, especially in the mid- and upper-troposphere; thus, the reduced convective fraction in POLL and SPOLL is not dependent on the particular choice of threshold $w$ to define convective updrafts. Weaker convection in POLL and SPOLL is attributed to stabilization of the troposphere caused by an increase in upper-tropospheric radiative heating (Fig. 14d), which is a direct result of the higher anvil top and greater $q_{\mathrm{i}}$. Greater radiative heating rates contribute to ensemble-mean upper-tropospheric temperatures that are up to $4 \mathrm{~K}$ higher in POLL and SPOLL compared to PRIS (Fig. 15a). 

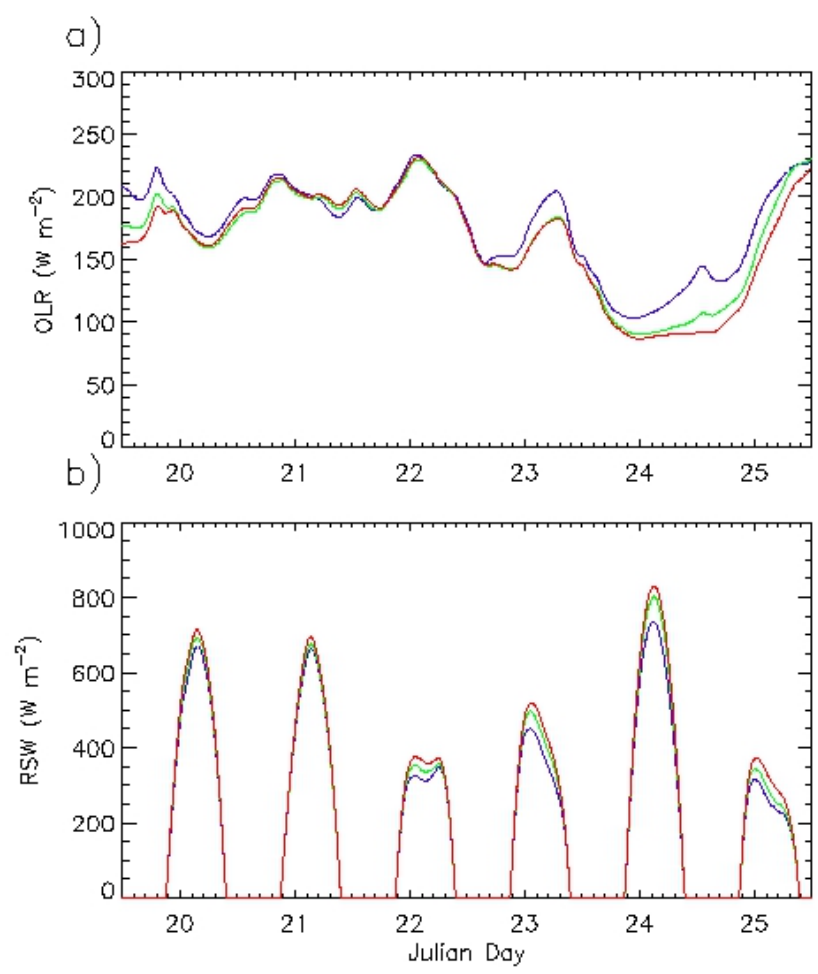

Fig. 12. Timeseries of ensemble- and horizontally-averaged TOA (a) outgoing longwave radiation (OLR) and (b) reflected shortwave radiation (RSW), for PRIS (blue), POLL (green), and SPOLL (red).

These results contrast with our analysis of individual realizations in Sect. 4, which were dominated by random fluctuations associated with individual convective events. Thus, for a single realization there is less constraint on the convective characteristics and there can be stronger convection even with an increase in tropopause heating and subsequent stabilization of the upper troposphere. Ensemble averaging minimizes the impact of random fluctuations, so that convective strength is more constrained by the overall rates of tropospheric destabilization.

An additional set of 240-member ensembles were run with either pristine or super-polluted aerosol conditions, but with the increase of $N_{\mathrm{i}}$ due to heterogeneous and homogeneous freezing of cloud droplets and rain turned off. Thus, $N_{\mathrm{i}}$ is not influenced at all by droplet freezing in these simulations, although changes in $q_{\mathrm{i}}$ due to freezing of $q_{\mathrm{c}}$ and $q_{\mathrm{r}}$ are unmodified. These runs definitively show that the increased upper tropospheric $q_{\mathrm{i}}$ and $N_{\mathrm{i}}$ and hence decreased OLR and weaker convection in polluted conditions are the direct result of freezing of larger number of cloud droplets. In these runs, the time- and ensemble-mean profiles of $q_{\mathrm{i}}$ and $N_{\mathrm{i}}$ are nearly identical between PRIS and SPOLL, and consequently radiative heating, OLR, and convective strength are also practically the same (not shown). There is still an increase in time-mean RSW of $12.3 \mathrm{~W} \mathrm{~m}^{-2}$ with increased aerosol load- ing due to the impact on cloud water and rain, which is only slightly smaller than the change in RSW in the baseline PRIS and SPOLL runs. These tests therefore suggest that much of the impact of aerosols on RSW is due to changes in liquid microphysics alone. Another interesting result from these simulations is that ensemble variability of OLR and RSW is greatly reduced (ensemble spread of time-mean OLR and RSW is less than $10 \mathrm{~W} \mathrm{~m}^{-2}$, while it exceeds $25 \mathrm{~W} \mathrm{~m}^{-2}$ in the baseline configuration). Thus, changes in $N_{\mathrm{i}}$ resulting from the freezing of $N_{\mathrm{c}}$ in different realizations (for given aerosol), which are associated with changes in convective updraft mass flux near the $200 \mathrm{hPa}$ level due to random fluctuations in convective strength (see Sect. 4), are a primary cause of the large ensemble variability of OLR and RSW in the baseline simulations.

To briefly summarize, the decrease in ensemble-mean OLR in polluted compared to pristine conditions is mostly due to changes in ice microphysics. These changes are a direct result of the freezing of larger numbers of cloud droplets in the polluted runs. Increases in anvil height, $q_{\mathrm{i}}$, and $N_{\mathrm{i}}$ in polluted conditions are not a result of convective invigoration; convection is actually slightly weaker in the polluted runs because of the impact of changes in anvil characteristics on upper-tropospheric radiative heating. Larger $N_{\mathrm{i}}$ in turn results in smaller $r_{\mathrm{ei}}$ (Fig. 16a) and increased anvil emissivity, as well as a reduced mean mass-weighted fallspeed (Fig. 16b). A reduced ice sedimentation flux is consistent with increased $q_{\mathrm{i}}$ near cloud top and reduced $q_{\mathrm{i}}$ at lower levels (Fig. 13c). A small increase in RH between about 150 and $300 \mathrm{hPa}$ (Fig. 15b) is consistent with moistening associated with the decreased ice sedimentation flux.

\section{Sensitivity tests}

In this section we explore how different model configurations impact aerosol effects on clouds and radiation. Given large variability we again use the ensemble approach with 240 members each for PRIS and POLL and for each configuration for the sensitivity tests. The focus here is mainly on the impact of aerosols on OLR and RSW, since the impact on surface precipitation and other terms in the $\langle s\rangle,\langle q\rangle$, and $\langle h\rangle$ budgets is minimal for the same reasons discussed in previous sections. First, we discuss various tests with modified microphysical parameter settings, followed by discussion of tests using modified domain configurations (domain size and horizontal gridlength). A list of all sensitivity runs described in this section is given in Table 3 .

\subsection{Microphysical parameter tests}

Several studies have highlighted sensitivity of CSRM simulations of deep convection to microphysics parameter settings (e.g. Lord et al., 1984; Fovell and Ogura, 1988; McCumber et al., 1991; Ferrier et al., 1995; Liu et al., 1997; Gilmore 


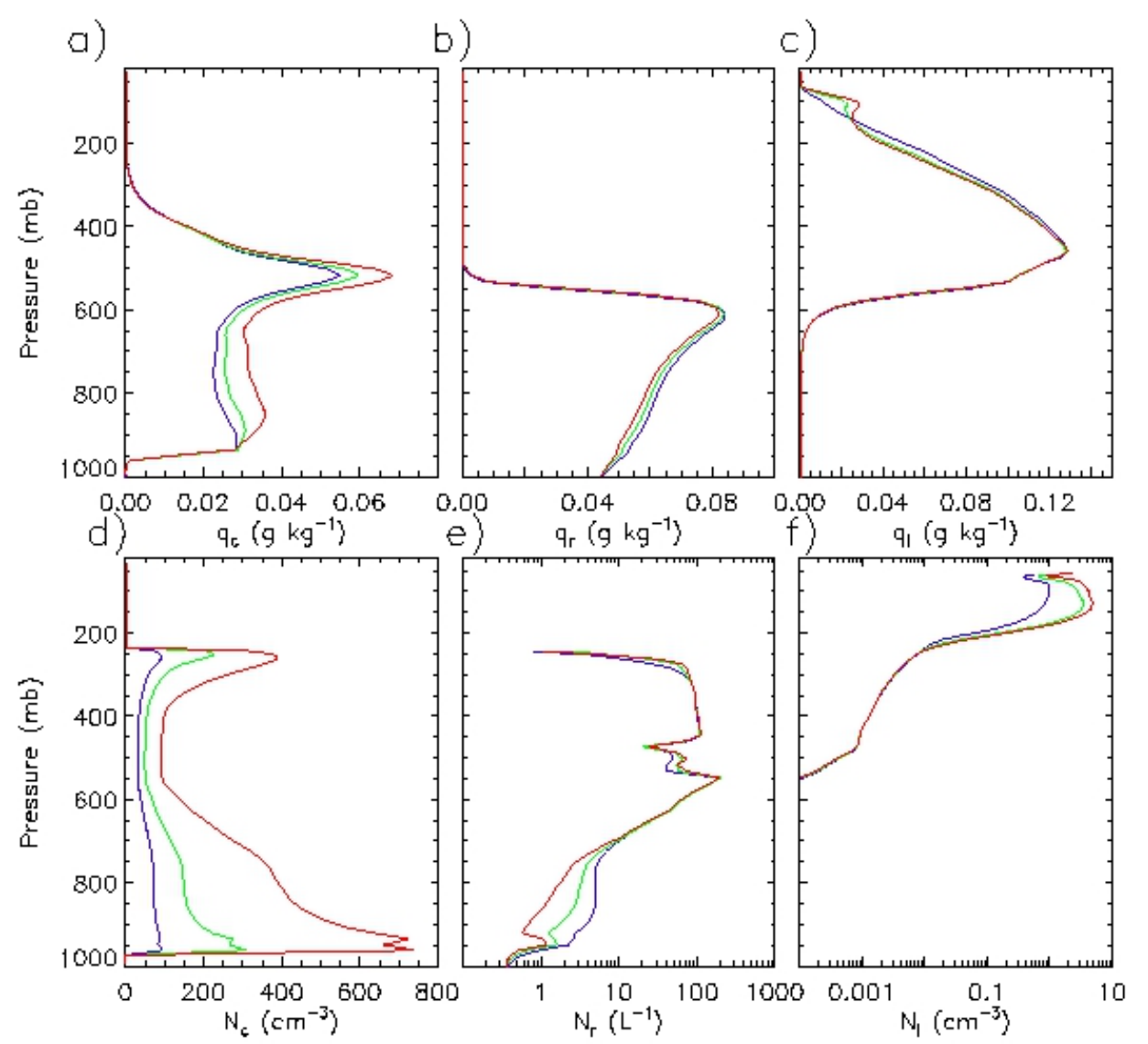

Fig. 13. Profiles of ensemble- and horizontally-averaged (a) cloud water mixing ratio, $q_{\mathrm{c}}$, (b) rain mixing ratio, $q_{\mathrm{r}}$, (c) ice mixing ratio, $q_{\mathrm{i}}$, (d) cloud droplet concentration, $N_{\mathrm{c}}$, (e) rain number concentration, $N_{\mathrm{r}}$, and (f) ice number concentration, $N_{\mathrm{i}}$, for PRIS (blue), POLL (green), and SPOLL (red). Presented results are averaged between 12:00 UTC 19 January to 12:00 UTC 25 January. Number concentrations are averaged over grid cells with mixing ratio greater than $0.001 \mathrm{~g} \mathrm{~kg}^{-1}$ for the given hydrometeor species.

Table 3. List of the ensemble sensitivity tests described in Sect. 6.

\begin{tabular}{ll}
\hline Name & Description \\
\hline BASE & Baseline model configuration (horizontal grid spacing of $1 \mathrm{~km}$; horizontal domain length of 200 km) \\
\hline GRPL & Graupel density of Locatelli and Hobbs (1974) replaced by Heymsfield and Kajikawa (1987) \\
\hline HET & $\begin{array}{l}\text { Heterogeneous cloud droplet and rain drop freezing rain of Bigg (1953) replaced by Barklie and } \\
\text { Gokhale (1959) }\end{array}$ \\
\hline HAB & $\begin{array}{l}\text { Mass-dimension relation for unrimed crystals corresponding to aggregates of side planes, bullets, and } \\
\text { columns (Mitchell et al., 1990) in BASE is replaced by that from Brown and Francis (1995). }\end{array}$ \\
\hline $4 \mathrm{~km}$ & Horizontal grid length increased to $4 \mathrm{~km}$ \\
\hline $2 \mathrm{~km}$ & Horizontal grid length increased to $2 \mathrm{~km}$ \\
\hline $0.5 \mathrm{~km}$ & Horizontal grid length decreased to $0.5 \mathrm{~km}$ \\
\hline LDOM & Horizontal domain length increased to $600 \mathrm{~km}$ \\
\hline
\end{tabular}



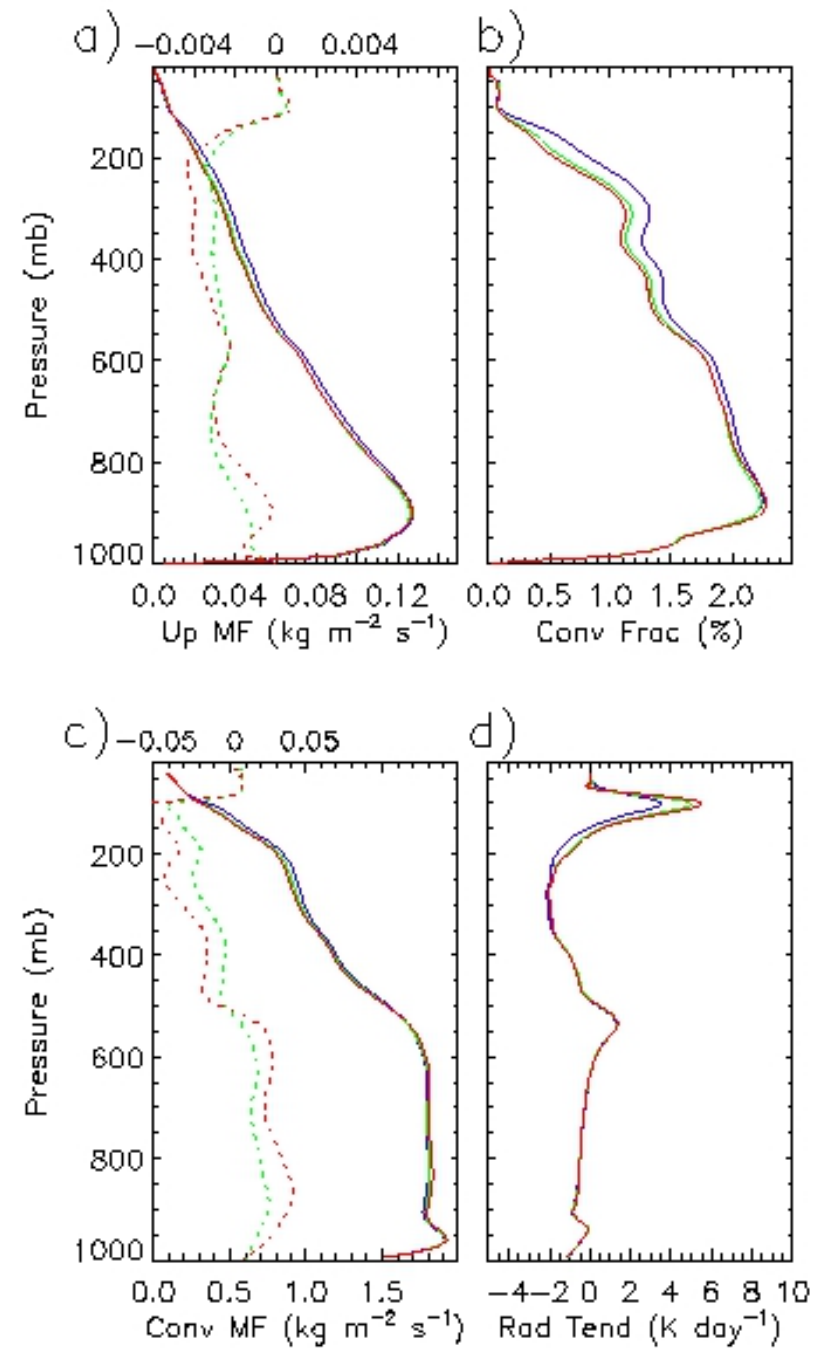

Fig. 14. As in Fig. 13, except for ensemble-average profiles of (a) updraft mass flux, (b) fraction of the domain containing convective updrafts, (c) convective updraft mass flux averaged over cells containing convective updrafts, and d) temperature tendency due to radiative heating, for PRIS (blue), POLL (green), and SPOLL (red). Also shown in (a) and (c) are differences between POLL and PRIS (green dotted line) and SPOLL and PRIS (red dotted line), with values shown on the axis at the top of the plots.

et al., 2004; Morrison et al., 2009; Morrison and Milbrandt, 2011). However, relatively few studies have focused on the impact of such parameter settings on aerosol effects on deep convective clouds and precipitation. Based on the results described in Sect. 5, we expect parameters that impact ice particle size, number concentration, and fallspeed to be particularly important. Thus, we test three different microphysical configurations that are key in determining ice characteristics: (1) heterogeneous droplet freezing (HET), (2) graupel density expressed by the mass-dimension $(m-D)$ relation (GRPL), and (3) ice particle habit, as expressed through

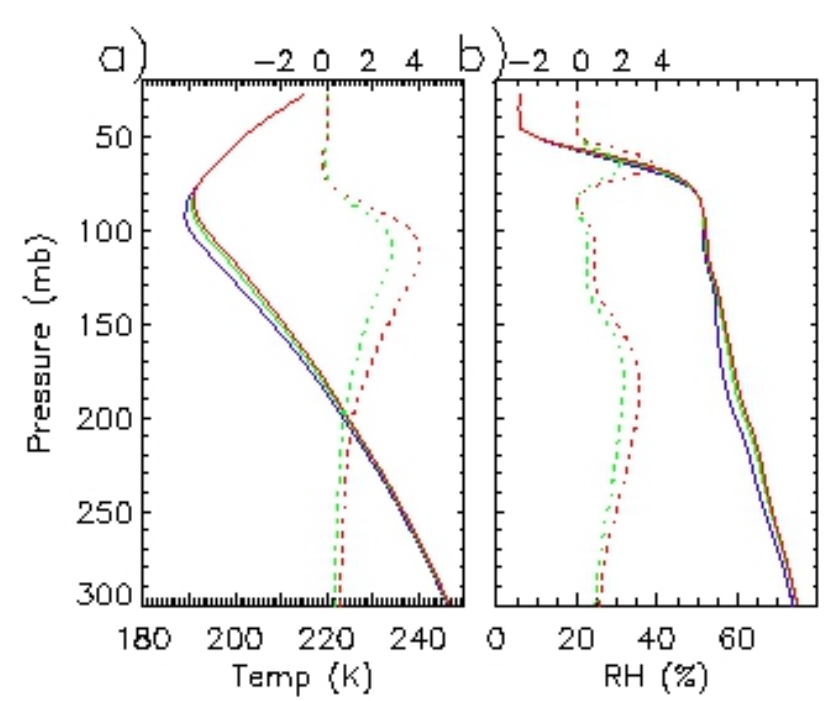

Fig. 15. As in Fig. 13, except for ensemble-average profiles of (a) temperature and (b) relative humidity, for PRIS (blue), POLL (green), and SPOLL (red). Also shown are differences between POLL and PRIS (green dotted line) and SPOLL and PRIS (red dotted line), with values shown on the axis at the top of the plots.

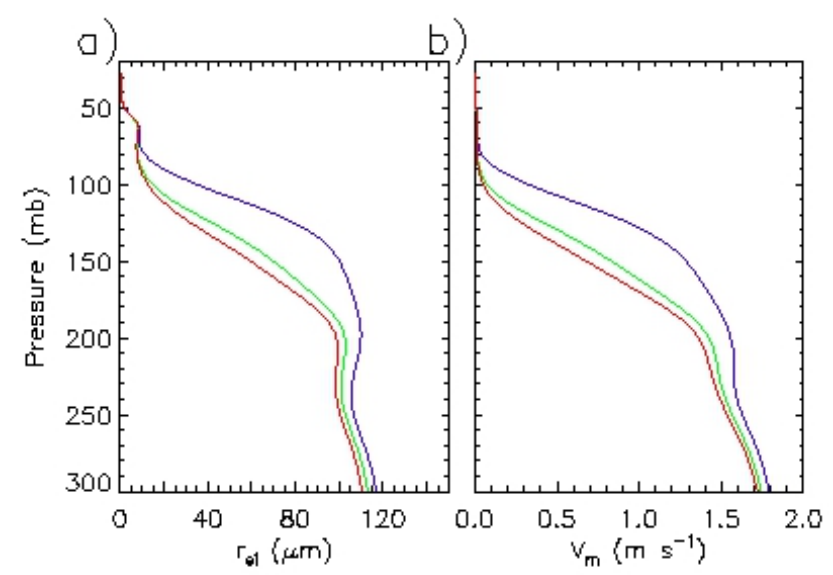

Fig. 16. Vertical profiles of ensemble- and horizontally-averaged mass-weighted (a) ice effective radius, $r_{\mathrm{ei}}$, and (b) ice particle fallspeed, $V_{\mathrm{m}}$, for PRIS (blue), POLL (green), and SPOLL (red). Presented results are averaged between 12:00 UTC 19 January and 12:00 UTC 25 January.

the $m-D$ relation for unrimed and partially-rimed ice crystals (HAB). In HET, the parameterization of droplet freezing of Bigg (1953) in BASE is replaced by Barklie and Gokhale (1959), which reduces the freezing rate by roughly one to two orders of magnitude. In GRPL, the $m-D$ relation for graupel following Locatelli and Hobbs (1974) in BASE is replaced by Heysmfield and Kajikawa (1987), resulting in roughly a factor of 3 decrease in particle density. Finally, in HAB the $m-D$ relation for unrimed crystals corresponding 
to aggregates of side planes, bullets, and columns (Mitchell et al., 1990) in BASE is replaced by that of Brown and Francis (1995). Note that this $m-D$ relation also affects partially-rimed crystals in the scheme (see Morrison and Grabowski, 2008b, for details). Changes in the $m-D$ relations for the both the GRPL and HAB tests impact several ice microphysical processes, including fallspeed and rates of diffusional growth and riming.

The magnitude of aerosol effects on OLR and RSW vary considerably between the different microphysical configurations, although all settings produce a statistically-significant decrease in time- and ensemble-mean OLR and increase in RSW in polluted compared to pristine conditions (Table 4). In GRPL, the reduction of graupel density leads to lower fallspeed of rimed ice, which accentuates differences in uppertropospheric ice characteristics between PRIS and POLL. The opposite occurs in HET and HAB with decreased droplet freezing rate and changes in $m-D$ relationship for pristine ice, respectively. In particular, HET highlights the important role of heterogeneous droplet freezing in explaining the large decrease of OLR in polluted conditions in BASE. With the large reduction of heterogeneous freezing rates in HET, mean $N_{\mathrm{i}}$ is reduced by a factor of roughly $2-4$ relative to BASE in polluted conditions and differences in $N_{\mathrm{i}}$ between PRIS and POLL are smaller. However, the significance of this result is unclear since differences in $N_{\mathrm{i}}$ and OLR between HET and BASE are much smaller for super polluted conditions. Smaller aerosol effects on the TOA radiative fluxes in HET and $\mathrm{HAB}$ also result in reduced impacts on $F_{\mathrm{R}}$. The impact of aerosols on the other forcing terms in the $s, q$, and $h$ budgets with increased aerosol loading are very small and generally not statistically significant (see Table 4).

\subsection{Domain configuration tests}

Numerous studies have investigated sensitivity of CSRM simulations to domain size and horizontal gridlength, $\Delta x$ (e.g. Grabowski et al., 1998; Adlerman and Droegemeier, 2002; Petch and Gray, 2001; Bryan et al., 2003; Dawson et al., 2010; Bryan and Morrison, 2011). As is the case for microphysical parameter sensitivity, there has relatively little testing of the impact of domain size and $\Delta x$ on indirect aerosol effects. Four sensitivity pairs of ensembles are run for these tests: (1) $\Delta x=4 \mathrm{~km}(4 \mathrm{~km})$, (2) $\Delta x=2 \mathrm{~km}(2 \mathrm{~km})$, (3) $\Delta x=0.5 \mathrm{~km}(0.5 \mathrm{~km})$, and (4) horizontal domain length increased from 200 to $600 \mathrm{~km}$ (using $\Delta x=1 \mathrm{~km}$ as in baseline) (LDOM).

Ensemble-mean differences in OLR and RSW between POLL and PRIS in these tests are similar to BASE, although the magnitude of aerosol effects is about half as large in $4 \mathrm{~km}$ and $2 \mathrm{~km}$ compared to BASE and $0.5 \mathrm{~km}$ (Table 4). Specific reasons for this difference are unclear, but may be related to the marginal ability of models with $\Delta x$ of a few $\mathrm{km}$ or greater to resolve deep convective motion, attributable to reduced intensity of nonhydrostatic processes associated with larger cell size (cf. Weisman et al., 1997; Bryan et al., 2003). There is little difference in simulations with a decrease of $\Delta x$ from $1 \mathrm{~km}$ (BASE) to $0.5 \mathrm{~km}$, or with the increase in domain size (LDOM). Aerosols have little impact on other forcing terms in the $s, q$, and $h$ budgets with changes in $\Delta x$ or domain size. There is a general decrease in ensemble standard deviation in LDOM compared to BASE owing to the larger sampling space, although the differences are fairly small. For example, ensemble standard-deviation of time-mean OLR is roughly $30 \%$ smaller in LDOM than BASE, while it is reduced by roughly $15 \%$ for RSW. Ensemble standard deviation is similar to BASE for the sensitivity tests with different horizontal grid spacing. Time- and ensemble-mean OLR and RSW for all sensitivity configurations, including changes to microphysics, are within the ensemble spread for BASE. This result highlights the importance of considering ensemble variability when testing model sensitivity to various parameter settings.

\section{Discussion and conclusions}

In this study we examined the impact of aerosols on deep convection and anvil cirrus in CSRM simulations of a six-day period of active monsoon conditions during TWP-ICE. The baseline configuration for the model used a $200 \times 24 \mathrm{~km} 2$-D domain and $1 \mathrm{~km}$ horizontal grid spacing. The two-moment bulk scheme of Morrison and Grabowski (2007, 2008a, b) was used as the microphysics parameterization.

A key finding is that different realizations (generated by different initial seeds for small, random perturbations applied to the low-level $\theta$ field) produced large differences (exceeding $25 \mathrm{~W} \mathrm{~m}^{-2}$ ) in the domain-averaged OLR and RSW even when averaged over the six-day analysis period. This result was attributed to random fluctuations and inherent low level of predictability in the strength of deep convection that resulted in somewhat greater convective mass flux near the $200 \mathrm{hPa}$ level in the low-OLR (high-RSW) compared to highOLR (low-RSW) realizations, and subsequently to greater anvil height, $q_{\mathrm{i}}$, and $N_{\mathrm{i}}$. Ensemble averaging minimizes the impact of these random fluctuations, so that ensemble-mean convective strength was more constrained by the overall thermodynamic characteristics and rate of tropospheric destabilization. Ensemble variability is likely to be reduced using a three-dimensional (3-D) model given the larger sampling space compared to 2-D (Donner et al., 1999; Grabowski et al., 1999). However, spatial correlation of quantities in the third dimension would limit the effective sampling space in 3 -D, especially if the domain is small as in "bowling-alley" simulations (e.g. Tompkins, 2001). Other factors such as type of convective organization are likely to play a role; further work is needed to quantify this variability for different cases and domain configurations.

Differences in other terms in the $s, q$, and $h$ budgets between realizations were small, especially when averaged 
Table 4. Results of ensemble tests described in Table 3. Presented quantities are differences in ensemble means between polluted and pristine conditions (POLL minus PRIS) averaged from 12:00 UTC 19 January to 12:00 UTC 25 January. Values in parentheses indicate an average of the ensemble standard deviation for the pristine and polluted ensembles. Statistically-significant differences (95\% confidence level) are shown in bold. Units are $\mathrm{W} \mathrm{m}^{-2}$.

\begin{tabular}{lrrrrrr}
\hline Run & OLR & RSW & $F_{\mathrm{L}}$ & $F_{S}$ & $F_{\mathrm{R}}$ & $F_{\mathrm{P}}$ \\
\hline BASE & $\mathbf{- 1 0 . 6}(6.0)$ & $\mathbf{1 0 . 7}(5.5)$ & $\mathbf{- 1 . 7}(5.4)$ & $-0.5(0.7)$ & $\mathbf{8 . 9}(5.4)$ & $\mathbf{- 2 . 8}(8.0)$ \\
GRPL & $\mathbf{- 1 4 . 1}(3.6)$ & $\mathbf{1 6 . 2}(5.9)$ & $\mathbf{- 0 . 8}(4.8)$ & $-0.3(0.6)$ & $\mathbf{1 2 . 6}(3.1)$ & $\mathbf{- 6 . 1}(7.4)$ \\
HET & $\mathbf{- 2 . 5}(5.0)$ & $\mathbf{5 . 7}(4.1)$ & $0.1(5.5)$ & $-0.2(0.7)$ & $\mathbf{2 . 2}(4.4)$ & $-0.5(8.7)$ \\
HAB & $-\mathbf{3 . 7}(5.3)$ & $\mathbf{7 . 6}(8.5)$ & $-0.2(4.7)$ & $-0.3(0.5)$ & $\mathbf{3 . 3}(4.5)$ & $-0.1(8.1)$ \\
$4 \mathrm{~km}$ & $\mathbf{- 5 . 3}(5.5)$ & $\mathbf{8 . 5}(6.7)$ & $-0.5(5.3)$ & $-0.4(0.5)$ & $\mathbf{4 . 5}(5.0)$ & $-0.4(8.6)$ \\
$2 \mathrm{~km}$ & $-\mathbf{5 . 0}(5.6)$ & $\mathbf{6 . 6}(5.0)$ & $-0.6(5.2)$ & $-0.4(0.6)$ & $\mathbf{4 . 4}(5.0)$ & $-0.6(8.5)$ \\
$0.5 \mathrm{~km}$ & $-\mathbf{1 0 . 3}(5.2)$ & $\mathbf{1 1 . 2}(5.3)$ & $-\mathbf{2 . 3}(6.1)$ & $-0.4(0.8)$ & $\mathbf{8 . 6}(4.7)$ & $\mathbf{- 3 . 8}(8.3)$ \\
LDOM & $\mathbf{- 1 2 . 7}(4.1)$ & $\mathbf{1 1 . 3}(4.8)$ & $\mathbf{- 2 . 7}(5.2)$ & $-0.5(0.5)$ & $\mathbf{8 . 9}(3.7)$ & $\mathbf{- 4 . 9}(7.6)$ \\
\hline
\end{tabular}

over periods longer than 6-12 h. Fairly constant profiles of $s$ in time and large column saturation fractions meant that there was a strong constraint on surface precipitation. Thus, the $q$ budget was mostly a balance between moistening from the applied large-scale forcing and drying from precipitation, with little change in atmospheric storage. Similarly, the $s$ budget was mostly a balance between cooling from largescale forcing and diabatic heating. This stiff constraint on precipitation also meant that there was little sensitivity to aerosols, with precipitation almost entirely controlled by the applied large-scale forcing and, to a lesser extent, the surface latent heat fluxes (which in turn were strongly constrained by the constant SST and nudging of horizontal wind).

The large spread in OLR and RSW due to random fluctuations of convective strength among realizations meant that a statistically-significant aerosol indirect effect could only be determined using large-member ensembles. To address this issue, we ran 240-member ensembles each for pristine, polluted, and highly polluted aerosol conditions. There was a statistically-significant aerosol indirect effect on OLR and RSW; ensemble- and time-mean OLR decreased $13.4 \mathrm{~W} \mathrm{~m}^{-2}$ and RSW increased $19.0 \mathrm{~W} \mathrm{~m}^{-2}$ in highly polluted compared to pristine conditions. Changes in OLR and RSW approximately canceled for polluted compared to pristine, with a net energy flux change at the TOA of $-5.6 \mathrm{~W} \mathrm{~m}^{-2}$ for highly polluted compared to pristine. Changes in RSW were driven mostly by changes in liquid microphysics alone, while increased OLR was due to greater height, ice mixing ratio, and ice number concentration of anvil cirrus in polluted conditions.

Greater optical thickness and height of polluted clouds is qualitatively consistent with recent satellite observational studies (e.g. Koren et al., 2008, 2010a, b; Massie et al., 2011). Some studies hypothesized that these impacts were driven by aerosol-induced convective invigoration (Koren et al., 2005, 2008, 2010a, b; Rosenfeld et al., 2008). However, changes in anvil characteristics occurred here as a direct result of freezing of larger number of cloud droplets in polluted conditions that led to decreased ice effective radius, particle fallspeed, and ice sedimentation flux, not as a result of convective invigoration. Time- and ensemble-mean convective mass fluxes were actually slightly weaker above $500 \mathrm{hPa}$ in polluted conditions because of upper-tropospheric radiative heating and stabilization caused by the changes in anvil ice characteristics. Thus, our results suggest a possible alternative interpretation of observations showing increases in anvil height and optical thickness in polluted conditions. Here we investigated the impact of aerosols on tropical convection over a large domain and multi-day period with several cloud lifecycles, which is arguably more relevant to climate, in contrast to previous studies that have mainly investigated aerosol impacts on individual clouds or convective systems. Our results should therefore be strictly interpreted in the context of a system consisting of numerous convective clouds that interact spatially and temporally, and do not necessarily provide evidence that contradicts previous modeling studies indicating aerosol-induced invigoration of individual convective systems when considered in isolation (e.g. Khain et al., 2005; Lynn et al., 2005; Lee et al., 2008; Khain, 2009; Fan et al., 2009).

Our results demonstrate the importance of feedbacks between convection and the thermodynamic environment; changes in convective dynamics or microphysics impact the environment, which in turn feeds back to the clouds and convection. Such feedbacks can exert a strong constraint on quantities like surface precipitation, which is largely controlled by forcing terms in the $s, q$, and $h$ budgets. The systems dynamics viewpoint, which includes various interactions and feedbacks in the system, is consistent with CRE simulations of Grabowski (2006) and Grabowski and Morrison (2011). This viewpoint contrasts process-level reasoning that is more applicable to an individual cloud or cloud system. Thus, we might expect that large forced changes in convective strength (for example, from enhanced latent heating in updrafts following Rosenfeld et al., 2008) would be reduced over time because of adjustment of the environment, 
so that the updraft mass flux would subsequently be controlled by the rate of tropospheric destabilization through surface fluxes and tropospheric radiative flux divergence as in CRE, or by feedback with the larger-scale dynamics. We are currently exploring this hypothesis and results will be reported in a future publication.

To further test the robustness of these results, we used the ensemble approach contrasting PRIS and POLL but with different model configurations. Microphysical parameters that were varied included heterogeneous droplet freezing rate, graupel density, and $m-D$ relation for unrimed crystals. Additional tests modified horizontal gridlength (from 0.5 to $4 \mathrm{~km}$ ) and horizontal domain length (200 to $600 \mathrm{~km}$ ). Ensemble-mean differences in OLR and RSW between POLL and PRIS were qualitatively similar among the different configurations, although there were quantitative differences of several $\mathrm{W} \mathrm{m}^{-2}$. In particular, much smaller differences in OLR between POLL and PRIS when heterogeneous droplet freezing rates were reduced indicate the importance of ice nucleation and especially the parameterization of heterogeneous droplet freezing. These results highlight the need for improved estimates of microphysical parameter settings to reduce uncertainty in simulations of aerosol indirect effects. Surface fluxes and precipitation were insensitive to aerosols in all the configurations that were tested because of the constraints described above.

We emphasize that feedbacks between the convectivescale and larger-scale dynamics were neglected in this study. This approach allowed us to simulate the impact of aerosols on clouds and convection in a framework that included realistic time-dependent forcing and feedback with the thermodynamic environment, but without complications arising from feedbacks with larger scale dynamics. Although we expect interactions between aerosols, microphysics, and convection to be strongly constrained by feedback to the environment as argued above, these interactions are expected to also be modulated by feedbacks with larger scale dynamics. For example, an initial invigoration of convection and increased diabatic heating induced by aerosols may lead to compensating large-scale ascent and adiabatic cooling in the convectivelyactive region, driving horizontal convergence of $q$ that could help to sustain stronger convection and precipitation in the area of active convection. Aerosol-induced changes in anvil characteristics, as occurred here, may also be expected to impact horizontal gradients of upper-tropospheric radiative heating, which in turn could impact larger-scale circulations and convective coupling (Bretherton et al., 2005; Stephens et al., 2008). In reality, such feedbacks are likely to be complicated by interactions with mesoscale organization and convectively-coupled waves that dominate variability of the tropical atmosphere (e.g. Wheeler and Kiladis, 1999). In future work we plan to investigate the impact of feedbacks between convection and larger scales in the context of indirect aerosol effects using both idealized and realistic model configurations.
We also emphasize that these simulations utilized a fixed SST. Changes in surface conditions provide another pathway whereby aerosols could affect surface heat fluxes and hence the water and static energy budgets and tropospheric destabilization. We also neglected the direct impact of aerosols of radiation through scattering or absorption, which can influence tropospheric destabilization and hence convective characteristics (e.g. Hansen et al., 1997; Ackerman et al., 2000; Koren et al., 2004).

Several simplifying assumptions were made with regard to microphysics and cloud-aerosol interactions. The specified background aerosol was treated as constant in space and time; thus, while aerosols impacted cloud microphysics there was no feedback of clouds back on aerosols (aerosol concentration was assumed to revert back to the background concentration upon dissipation of the cloud). Removal of aerosols by scavenging from cloud and precipitation particles may be important for quantifying aerosol impacts on deep convection (e.g. Lee and Feingold, 2010; Ekman et al., 2011). Here we utilized a simplified approach given the large uncertainty and difficulty in representing aerosol source and sink terms (e.g. large-scale forcing, surface sources, etc.). Our results therefore represent an upper limit on the magnitude of aerosol indirect effects if wet removal by scavenging is dominant and reduces aerosol loading over time. This simplification is not expected to alter our main conclusion that aerosols do not invigorate convection when averaged over the six-day period and have little impact on surface precipitation even in highly polluted conditions in our modeling framework.

The treatment of ice nucleation was also simplified by neglecting the impact of aerosol loading on concentrations of homogeneous and heterogeneous IN, except indirectly via cloud droplet and rain drop freezing. Aerosol loading could impact homogeneous and heterogeneous ice nucleation, but the relationship between aerosol characteristics and IN concentration remains highly uncertain (Cantrell and Heymsfield, 2005; Fridlind et al., 2007). However, it seems likely that changes in IN concentration with aerosol loading would not alter our finding that ice number concentration, $N_{\mathrm{i}}$, increases with pollution. There is observational support for increased $N_{\mathrm{i}}$ and/or decreased ice effective radius, $r_{\mathrm{ei}}$, in polluted conditions. Satellite retrievals have indicated smaller $r_{\mathrm{ei}}$ for deep convective and anvil clouds in polluted conditions (Sherwood et al., 2002; Jiang et al., 2011). Heymsfield et al. (2009) analyzed aircraft observations in the eastern tropical Atlantic and found substantial increases in droplet and ice particle concentrations associated with aerosol intrusions at low- and mid-levels, with particles activating as cloud droplets before freezing near the $-40{ }^{\circ} \mathrm{C}$ level and producing high concentrations of ice particles. Detailed comparison with observational analyses is needed to validate the model and findings reported herein.

An important conclusion is that fairly small changes in upper-tropospheric convective characteristics can have a large impact on anvil ice properties. In particular, a small 
increase in the convective mass flux near the $200 \mathrm{hPa}$ level in some realizations led to large increases in $N_{\mathrm{i}}$ and $q_{\mathrm{i}}$, in part by impacting the upward mass flux of liquid water and number concentration of droplets that freeze. Previous studies have indicated sensitivity of convective mass fluxes to dimensionality (e.g. Phillips and Donner, 2006; Petch et al., 2008) and horizontal grid spacing (Bryan et al., 2003; Bryan and Morrison, 2011). For example, Bryan and Morrison (2011) showed that decreasing the horizontal grid spacing from $1 \mathrm{~km}$ to $250 \mathrm{~m}$ led to a decrease in anvil height and $q_{\mathrm{i}}$ in simulations of a mid-latitude squall line, mainly due to increased entrainment and weakening of convective drafts with higher resolution. In future work we plan to extend the study of Bryan and Morrison (2011) by investigating the impact of horizontal grid spacing on changes in entrainment for tropical deep convection, with a focus on how this affects the upward flux of liquid water near the homogeneous freezing level and anvil ice characteristics in the context of aerosol indirect effects.

Acknowledgements. National Center for Atmospheric Research is sponsored by the National Science Foundation. This work was supported by the NOAA grant NA08OAR4310543, US DOE ARM DE-FG02-08ER64574, and the NSF Science and Technology Center for Multiscale Modeling of Atmospheric Processes (CMMAP), managed by Colorado State University under cooperative agreement ATM-0425247. We thank S. Massie for helpful discussions and Z. Piotrowski for help setting up the ensemble simulations.

Edited by: P. Spichtinger

\section{References}

Ackerman, S., Toon, O. B., Stevens, D. E., Heymsfield, A. J., Ramanathan, V., and Welton, E. J.: Reduction of tropical cloudiness, Science, 288, 1042-1047, 2000.

Albrecht, B. A.: Aerosols, cloud microphysics, and fractional cloudiness, Science, 245, 1227-1230, 1989.

Adlerman, E. J. and Droegemeier, K. K.: The sensitivity of numerically simulated cyclic mesocyclogenesis to variations in model physical and computational parameters, Mon. Weather Rev., 130, 2671-2691, 2002.

Allen, G., Vaughan, G., Bower, K. N., Williams, P. I., Crosier, J., Flynn, M., Connolly, P., Hamilton, J. F., Lee, J. D., Saxton, J. E., Watson, N. M., Gallagher, M., Coe, H., Allan, J., Choularton, T. W., and Lewis, A. C.: Aerosol and trace gas measurements in the Darwin area during the wet season, J. Geophys. Res., 113, D06306, doi:10.1029/2007JD008716, 2008.

Back, L. E. and Bretherton, C. S.: The relationship between wind speed and precipitation in the Pacific ITCZ, J. Climate, 18, 43174328, 2005.

Barklie, R. H. D. and Gokhale, N. R.: The freezing of supercooled water drops. Stormy Weather Group, McGill Univ., Sci. Rep. MW-30, Part III, 43-64, 1959.

Bigg, E. K.: The supercooling of water, Proc. Phys. Soc., B., 56, 688-694, 1953.
Bretherton, C. S., Peters, M. E., and Back, L. E.: Relationships between water vapor path and precipitation over the tropical oceans, J. Climate, 17, 1517-1528, 2004.

Bretherton, C. S., Blossey, P. N., and Khairoutdinov, M.: An energy-balance analysis of deep convective self-aggregation above uniform SST, J. Atmos. Sci., 62, 4273-4292, 2005.

Brown, P. R. A. and Francis, P. N.: Improved measurements of the ice water content in cirrus using a total water probe, J. Atmos. Oceanic Technol., 12, 410-414, 1995.

Bryan, G. H. and Morrison, H.: Sensitivity of a simulated squall line to horizontal resolution and parameterization of microphysics, Mon. Weather Rev., in press, 2011.

Bryan, G. H., Wyngaard, J. C., and Fritsch, J. M.: Resolution requirements for the simulation of deep moist convection, Mon. Weather Rev., 131, 2394-2416, 2003.

Cantrell, W. and Heymsfield, A. J.: Production of ice in tropospheric clouds: A review, B. Am. Meteorol. Soc., 86, 795-807, 2005.

Connolly, P. J., Choularton, T. W., Gallagher, M. W., Bower, K. N., Flynn, M. J., and Whiteway, J. A.: Cloud-resolving simulations of intense tropical Hector thunderstorms: Implications for aerosol-cloud interactions, Q. J. Roy. Meteor. Soc., 132, 30793106, 2006.

Dawson, D. T., Xue, M., Milbrandt, J. A., and Yau, M. K.: Comparison of evaporation and cold pool development between singlemoment and multimoment bulk microphysics schemes in idealized simulations of tornadic thunderstorms, Mon. Weather Rev., 138, 1152-1171, 2010.

Devasthale, A., Kruger, O., and Grassel, H.: Change in cloud-top temperature over Europe. IEEE Geosci. Remote. Sens., 2, 333336, 2005.

Donner, L. J., Seman, C. S., and Hemler, R. S.: Three-dimensional cloud-system modeling of GATE convection, J. Atmos. Sci., 56, 1885-1912, 1999.

Ekman, A. M., Engstrom, A., and Wang, C.: The effect of aerosol composition and concentration on the development and anvil properties of a continental deep convective cloud, Q. J. Roy. Meteor. Soc., 133, 1439-1452, 2007.

Ekman, A. M. L., Engstrom, A., and Soderberg, A.: Impact of twoway aerosol-cloud interaction and changes in aerosol size distribution on simulated aerosol-induced deep convective cloud sensitivity, J. Atmos. Sci., 68, 685-698, 2011.

Fan, J., Zhang, R., Li, G., and Tao, W.-K.: Effects of aerosols and relative humidity on cumulus clouds, J. Geophys. Res., 112, D14204, doi:10.1029/2006JD008136, 2007.

Fan, J., Yuan, T., Comstock, J. M., Ghan, S., Khain, A., Leung, L. R., Li, Z., Martins, V. J., and Ovchinnikov, M.: Dominant role by vertical wind shear in regulating aerosol effects on deep convective clouds, J. Geophys. Res., 114, D22206, doi:10.1029/2009JD012352, 2009.

Fan, J., Comstock, J. M., and Ovchinnikov, M.: The cloud condensation nuclei and ice nuclei effects on tropical anvil characteristics and water vapor of the tropical tropopause layer, Env. Res. Lett., 5, 044055, doi:10.1088/1748-9326/5/4/044005, 2010.

Ferrier, B. S., Tao, W.-K., and Simpson, J.: A double-moment multiple-phase four-class bulk ice scheme. Part II: Simulations of convectgive storms in different large-scale environments and comparisons with other bulk parameterizations, J. Atmos. Sci., 52, 1001-1033, 1995. 
Fovell, R. G. and Ogura, Y.: Numerical simulation of a mid-latitude squall line in two dimensions, J. Atmos. Sci., 45, 3846-3879, 1988.

Fowler, L. and Randall, D. A.: A global radiative-convective feedback, Geophys. Res. Lett., 21, 2035-2038, 1994.

Fridlind, A. M., Ackerman, A. S., McFarquhar, G., Zhang, G., Poellot, M. R., DeMott, P. J., Prenni, A. J., and Heymsfield, A. J.: Ice properties of single-layer stratocumulus during the Mixed-Phase Arctic Cloud Experiment (M-PACE): Part II, Model results, J. Geophys. Res., 112, D24202, doi:10.1029/2007JD008646, 2007.

Fridlind, A., Ackerman, A., Petch, J., Field, P., Hill, A., McFarquhar, G., Xie, S., and Zhang, M.: ARM/GCSS/SPARC TWPICE CRM Intercomparison Study, NASA-TM-2010-215858, National Aeronautics and Space Administration, 2010.

Fridlind, A. M., Ackerman, A. S., Chaboureau, J.-P., Fan, J., Grabowski, W. W., Hill, A., Jones, T. R., Liu, G., Morrison, H., Park, S., Petch, J. C., Pinty, J.-P., Schumacher, C., Varble, A. C., Wu, X., Xie, S., and Zhang, M.: A comparison of TWP-ICE observational data with cloud-resolving model results, J. Geophys. Res., submitted, 2011.

Gilmore, M. S., Straka, J. M., and Rasmussen, E. N.: Precipitation uncertainty due to variations in precipitation particle parameters within a simple microphysics scheme, Mon. Weather Rev., 132, 2610-2627, 2004.

Grabowski, W. W.: Coupling cloud processes with the large-scale dynamics using the Cloud-Resolving Convection Parameterization (CPRP), J. Atmos. Sci., 58, 978-997, 2001.

Grabowski, W. W.: An improved framework for superparameterization, J. Atmos. Sci., 61, 1940-1952, 2004.

Grabowski, W. W.: Indirect impact of atmospheric aerosols in idealized simulations of convective-radfiative equilibrium, J. Climate, 19, 4664-4682, 2006.

Grabowski, W. W. and Morrison, H., Impact of atmospheric aerosols in simulations of convective-radiative quasiequilibrium: Double-moment microphysics, J. Climate, 24, 1897-1912, 2011.

Grabowski, W. W. and Smolarkiewicz, P. K.: CRCP: A cloud resolving convection parameterization for modeling the tropical convecting atmosphere, Physica D, 133, 171-178, 1999.

Grabowski, W. W., Wu, X., and Moncrieff, M. W.: Cloud-resolving modeling of tropical cloud systems during Phase III of GATE. Part I: Two-dimensional experiments, J. Atmos. Sci., 53, 36843709, 1996.

Grabowski, W. W., Wu, X., Moncrieff, M. W., and Hall, W. D.: Cloud-resolving modeling of cloud systems during Phase III of GATE. Part II: Effects of resolution and the third spatial dimension, J. Atmos. Sci., 55, 3264-3282, 1998.

Grabowski, W. W., Wu, X., and Moncrieff, M. W.: Cloud resolving modeling of tropical cloud systems during Phase III of GATE. Part III: Effects of microphysical parameterizations, J. Atmos. Sci., 56, 2384-2402, 1999.

Grabowski, W. W., Thouron, O., Pinty, J.-P., and Brenguier, J.-L.: A hybrid bulk-bin approach to model warm-rain processes, J. Atmos. Sci., 67, 385-399, 2010.

Hack, J. J. and Pedretti, J. A.: Assessment of solution uncertainties in single-column modeling frameworks, J. Climate, 13, 352-365, 2000.

Hansen, J., Sato, M., and Reudy, R.: Radiative forcing and climate response, J. Geophys. Res., 102, 6831-6864, 1997.
Heysmfield, A. J. and Kajikawa, M.: An improved approach to calculating terminal velocities of plate-like crystals and graupel, J. Atmos. Sci., 44, 1088-1099, 1987.

Heymsfield, A. J., Bansemer, A., Heymsfield, G., and Fierro, A. O.: Microphysics of maritime tropical convective updrafts at temperatures from -20 to $-60^{\circ} \mathrm{C}$, J. Atmos. Sci., 66, 3530-3562, 2009.

Jiang, J. H., Su, H., Zhai, C., Massie, S. T., Schoeberl, M. R., Colarco, P. R., Platnick, S., Gu, Y., and Liou, K.-N.: Influence of convection and aerosol pollution on ice cloud particle effective radius, Atmos. Chem. Phys., 11, 457-463, doi:10.5194/acp-11457-2011, 2011.

Khain, A. P.: Notes on state-of-the-art investigation of aerosol effects on precipitation: A critical review, Env. Res. Lett., 4, 015004, doi:10.1088/1748-9326/4/1/015004, 2009.

Khain, A. P., Rosenfeld, D., and Pokrovsky, A.: Aerosol impact on the dynamics and microphysics of deep convective clouds, Q. J. Roy. Meteor. Soc., 131, 2639-2663, 2005.

Khairoutdinov, M. F. and Randall, D. A.: Cloud-resolving modeling of the ARM summer 1997 IOP: Model formulation, results, uncertainties and sensitivities, J. Atmos. Sci., 60, 607-625, 2003.

Kiehl, J. T., Hack, J. J., and Briegleb, B. P.: The simulated earth radiation budget of the National Center for Atmospheric Research community climate model CCM2 and comparisons with the Earth Radiation Budget Experiment (ERBE), J. Geophys. Res., 99, 20815-20827, 1994.

Koren, I., Kaufman, Y. J., Remer, L. A., and Martins, J. V.: Measurement of the effect of Amazon smoke on inhibition of cloud formation, Science, 303, 1342-1345, 2004.

Koren, I., Kaufman, Y. J., Rosenfeld, D., Remer, L. A., and Rudich, Y.: Aerosol invigoration and restructioning of Atlantic convective clouds, Geophys. Res. Lett., 32, L14828, doi:10.1029/2005GL023187, 2005.

Koren, I., Martins, J. V., Remer, L. A., and Afargan, H.: Smoke invigoration versus inhibition of clouds over the Amazon, Science, 321, 948-949, 2008.

Koren, I., Feingold, G., and Remer, L. A.: The invigoration of deep convective clouds over the Atlantic: aerosol effect, meteorology or retrieval artifact?, Atmos. Chem. Phys., 10, 8855-8872, doi:10.5194/acp-10-8855-2010, 2010a.

Koren, I., Remer, L. A., Altaratz, O., Martins, J. V., and Davidi, A.: Aerosol-induced changes of convective cloud anvils produce strong climate warming, Atmos. Chem. Phys., 10, 5001-5010, doi:10.5194/acp-10-5001-2010, 2010b.

Lebo, Z. J. and Seinfeld, J. H.: Theoretical basis for convective invigoration due to increased aerosol concentration, Atmos. Chem. Phys., 11, 5407-5429, doi:10.5194/acp-11-5407-2011, 2011.

Lee, S. S. and Feingold, G.: Precipitating cloud-system response to aerosol perturbations, Geophys. Res. Lett., 37, L23806, doi:10.1029/2010GL045596, 2010.

Lee, S. S., Donner, L. J., Phillips, V. T. J., and Ming, Y.: Examination of aerosol effects on precipitation in deep convective clouds during the 1997 ARM summer experiment, Q. J. Roy. Meteor. Soc., 134, 1201-1220, 2008.

Levin, Z. and Cotton, W. R.: Aerosol Pollution Impacts on Precipitation - A Scientific Review, Springer, 2009.

Liu, C., Moncrieff, M. W., and Zipser, E. J.: Dynamical influence of microphysics in tropical squall lines: A numerical study, Mon. Weather Rev., 125, 2193-2210, 1997. 
Locatelli, J. D. and Hobbs, P. V.: Fall speeds and masses of solid precipitating particles, J. Geophys. Res., 79, 2185-2197, 1974.

Lord, S. J., Willoughby, H. E., and Piotrowicz, J. M.: Role of parameterized ice-phase microphysics in an axisymmetric, nonhydrostatic tropical cyclone model, J. Atmos. Sci., 41, 2836-2848, 1984.

Lynn, B., Khain, A., Dudhia, J., Rosenfeld, D., Povrovsky, A., and Seifert, A.: Spectral (bin) microphysics coupled with a mesoscale model (MM5). Part I, Model description of first results, Mon. Weather Rev., 133, 44-58, 2005.

Massie, S. T., Bardeen, C., Delanoe, J., Munchak, L., Jiang, J. H., and Sui, H.: Observations of little cloud invigoration by aerosols, J. Geophys. Res., submitted, 2011

May, P. T., Mather, J. H., Vaughan, G., and Jakob, C.: Characterizing oceanic convective cloud systems - The Tropical Warm Pool International Cloud Experiment, B. Am. Meteor. Soc., 154, 153$155,2008$.

McCumber, M., Tao, W.-K., Simpson, J., Penc, R., and Soong, S.-T.: Comparison of ice-phase microphysical parameterization schemes using numerical simulations of tropical convection, J. Appl. Meteor., 30, 985-1004, 1991.

Meskhidze, N., Remer, L. A., Platnick, S., Negrón Juárez, R., Lichtenberger, A. M., and Aiyyer, A. R.: Exploring the differences in cloud properties observed by the Terra and Aqua MODIS Sensors, Atmos. Chem. Phys., 9, 3461-3475, doi:10.5194/acp-93461-2009, 2009.

Mitchell, D. L., Zhang, R., and Pitter, R. L.: Mass-dimensional relationships for ice particles and the influence of riming on snowfall rates, J. Appl. Meteor., 29, 153-163, 1990.

Morrison, H. and Grabowski, W. W.: Comparison of bulk and bin warm rain microphysics models using a kinematic framework, J. Atmos. Sci., 64, 2839-2861, 2007.

Morrison, H. and Grabowski, W. W.: Modeling supersaturation and sub-grid scale mixing with two-moment warm bulk microphysics, J. Atmos. Sci., 65, 792-812, 2008a.

Morrison, H. and Grabowski, W. W.: A novel approach for representing ice microphysics in models: Description and tests using a kinematic framework, J. Atmos. Sci., 65, 1528-1548, 2008 b.

Morrison, H. and Milbrandt, J. A.: Comparison of two-moment bulk microphysics schemes in idealized supercell thunderstorm simulations, Mon. Weather Rev., 139, 1103-1130, 2011.

Morrison, H., Thompson, G., and Tatarskii, V.: Impact of cloud microphysics on the development of trailing stratiform precipitation in a simulated squall line: Comparison of one- and two-moment schemes, Mon. Weather Rev., 137, 991-1007, 2009.

Petch, J. C. and Gray, M. E. B.: Sensitivity studies using a cloudresolving model simulation of the tropical west Pacific, Q. J. Roy. Meteor. Soc., 127, 2287-2306, 2001.

Petch, J. C., Blossey, P. N., and Bretherton, C. S.: Differences in the lower troposphere in two- and three-dimensional cloud-resolving model simulations of deep convection, Q. J. Roy. Meteor. Soc., 134, 1941-1946, 2008.

Peters, O. and Neelin, J. D.: Critical phenomena in atmospheric precipitation, Nature Physics, 2, 393-396, 2006.

Phillips, V. T. J. and Donner, L. J.: Cloud microphysics, radiation, and vertical velocities in two- and three-dimensional simulations of deep convection, Q. J. Roy. Meteor. Soc., 132, 3011-3033, 2006.

Phillips, V. T. J., Pokrovsky, A., and Khain, A.: The influence of time-dependent melting on the dynamics and precipitation production in maritime and continental storm clouds, J. Atmos. Sci., 64, 338-359, 2007.

Pruppacher, H. R. and Klett, J. D.: Microphysics of clouds and precipitation. Kluwer Academic Publishers, Dordrecht, The Netherlands, 954 pp., 1997.

Raymond, D. J.: Thermodynamic control of tropical rainfall, Q. J. Roy. Meteor. Soc., 126, 889-898, doi:10.1002/qj.49712656406, 2000.

Raymond, D. J., Sessions, S. L., and Fuchs, Z.: A theory for the spinup of tropical depressions, Q. J. Roy. Meteor. Soc., 133, 1743-1754, 2007.

Raymond, D. J., Sessions, S. L., Sobel, A. H., and Fuchs, Z.: The mechanics of gross moist stability, J. Adv. Model. Earth Syst., 1, 9, doi:10.3894/JAMES.2009.1.9, 2009.

Rosenfeld, D.: Suppression of rain and snow by urban and industrial air pollution, Science, 287, 1793-1796, 2000.

Rosenfeld, D., Lohmann, U., Raga, G. B., O’Dowd, C. D., Kumala, M., Fuzzi, S., Reissell, A., and Andrae, M. O.: Flood or drought: How do aerosols affect precipitation?, Science, 321, 1309-1313, 2008.

Satterthwaite, F. E.: An Approximate Distribution of Estimates of Variance Components, Biometrics Bulletin, 2, 110-114, 1946.

Seifert, A. and Beheng, K. D.: A two-moment cloud microphysics parameterization for mixed-phase clouds. Part 2: Maritime vs. continental deep convective storms, Meteor. Atmos. Phys., 92, 45-66, 2006

Sherwood, S. C.: Aerosols and ice particle size in tropical cumulonimbus, J. Climte, 15, 1051-1063, 2002.

Slawinska, J., Grabowski, W. W., and Morrison, H.: Impact of atmospheric aerosols on precipitation from deep organized convection: A prescribed-flow modeling study using double-moment bulk microphysics, Q. J. Roy. Meteor. Soc., 135, 1906-1913, 2009.

Sobel, A. H. and Bretherton, C. S.: Modeling tropical precipitation in a single column, J. Climate, 13, 4378-4392, 2000.

Solomon, S., Qin, D.,Manning, M., Marquis, M., Averyt, K., Tignor, M. M. B., Miller, Jr., H. L., and Chen, Z. (Eds.): Climate Change 2007: The Physical Science Basis, Cambridge University Press, 996 pp., 2007.

Stephens, G. L., van den Heever, S. C., and Pakula, L. A.: Radiative-convective feedbacks in idealized states of radiativeconvective equilibrium, J. Atmos. Sci., 65, 3899-3916, 2008.

Stevens, B. and Feingold, G.: Untangling aerosol effects on clouds and precipitation in a buffered system, Nature, 461, 607-613, 2009.

Tan, Z.-M., Zhang, F., Rotunno, R., and Snyder, C.: Mesoscale predictability of moist baroclinic waves: Experiments with parameterized convection, J. Atmos. Sci., 61, 1794-1804, 2004.

Tompkins, A. M.: Organization of tropical convection in low vertical low shears: The role of water vapor, J. Atmos. Sci., 58, 529-545, 2001.

Troen, I. and Mahrt, L.: A simple model of the atmospheric boundary layer: Sensitivity to surface evaporation, Bound.-Layer Meteor., 37, 129-148, 1986.

Twomey, S.: Pollution and planetary albedo, Atmos. Environ., 8, 1251-1256, 1974.

Twomey, S.: The influence of pollution of the shortwave albedo of clouds, J. Atmos. Sci., 34, 1149-1152, 1977. 
Van den Heever, S. C. and Cotton, W. R.: Urban aerosol impacts on downwind convective storms, J. Appl. Met. Clim., 46, 828-850, 2007.

Van den Heever, S. C., Carrio, G. G., Cotton, W. R., DeMott, P. J., and Prenni, A. J.: Impacts of nucleating aerosol on Florida storms. Part I: Mesoscale simulations, J. Atmos. Sci., 63, 17521775, 2006.

Van den Heever, S. C., Stephens, G. L., and Wood, N. B.: Aerosol indirect effects on tropical convective characteristics under conditions of radiative-convective equilibrium, J. Atmos. Sci., 68, 699-718, 2011.

Vaughan, G., Schiller, C., MacKenzie, A. R., Bower, K. N., Peter, T., Schlager, H., Harris, N. P. R., and May, P. T.: SCOUT03/ACTIVE: High-altitude aircraft measurements around deep tropical convection, B. Am. Meteor. Soc., 89, 647-662, 2008.

Warner, J.: A reduction in rainall associated with smoke from sugarcane files - An inadvertent weather modification?, J. Appl. Meteor., 7, 247-251, 1968.
Weisman, M. L., Skamarock, W. C., and Klemp, J. B.: The resolution dependence of explicitly modeled convective systems, Mon. Weather Rev., 125, 527-548, 1997.

Welch, B. L.: The generalization of "student's" problem when several different population variances are involved, Biometrika, 34, 28-35, 1947.

Wheeler, M. and Kiladis, G. N.: Convectively coupled equatorial waves: Analysis of clouds and temperature in the wavenumberfrequency domain, J. Atmos. Sci., 56, 374-399, 1999.

Xie, S., Hume, T., Jakob, C., Klein, S. A., McCoy, R., and Zhang, M.: Observed large-scale structures and diabatic heating and drying profiles during TWP-ICE, J. Climate, 23, 57-79, 2010.

Zhang, F., Bei, N., Rotunno, R., Snyder, C., and Epifanio, C. C.: Mesoscale predictability of moist baroclinic waves: Convectionpermitting experiments and multistage error growth dynamics, J. Atmos. Sci., 64, 3579-3594, 2007. 